\title{
Multiscale Systemic Risk and Its Spillover Effects in the Cryptocurrency Market
}

\author{
Xu Zhang ${ }^{1}{ }^{1}$ and Zhijing Ding $\mathbb{D}^{2}$ \\ ${ }^{1}$ School of Management Science and Engineering, Nanjing University of Information Science and Technology, \\ Nanjing 210044, China \\ ${ }^{2}$ Chang Wang School of Honors, Nanjing University of Information Science and Technology, Nanjing 210044, China \\ Correspondence should be addressed to Zhijing Ding; 201883200001@nuist.edu.cn
}

Received 16 February 2021; Revised 8 May 2021; Accepted 20 May 2021; Published 1 June 2021

Academic Editor: Ning Cai

Copyright ( $2021 \mathrm{Xu}$ Zhang and Zhijing Ding. This is an open access article distributed under the Creative Commons Attribution License, which permits unrestricted use, distribution, and reproduction in any medium, provided the original work is properly cited.

\begin{abstract}
Since the advent of Bitcoin, the cryptocurrency market has become an important financial market. However, due to the existence of the cryptocurrency bubble, investors face more difficulties in risk portfolios. We adopt wavelet packet decomposition, nonlinear Granger causality test, risk spillover network, and STVAR model; retain the mature research of multiscale systemic risk based on time and frequency; and thus extend systemic risk to different regimes. We found that when frequency is combined with regimes, the risk spillover center will undergo subversive changes in the long run. We also proposed that BTC will be more robust at extreme values (like longest and shortest periods), while cryptocurrencies with smaller market capitalization will be stronger in the medium term. At the same time, the recession period will also spur on it.
\end{abstract}

\section{Introduction}

In 2009, Nakamoto [1] proposed the concept of cryptocurrency and a proof system for encrypted payment. Thanks to its blockchain technology, Bitcoin does not involve intermediaries such as clearinghouses and is thus independent of sovereign risk [2]. At the same time, in 2017, the CME Group and the CBOE launched futures contracts with Bitcoin as an underlying asset, legitimizing it further. This has allowed Bitcoin to join commodities, including gold, in futures trading, and eventually move from the margins to the center of the financial world [3]. Accordingly, the cryptocurrency market has gradually gained much attention from speculators, investors, technology enthusiasts, and even the public. Due to its nonpolitical nature and commodity attributes [4], Bitcoin, the cryptocurrency of largest market value, is often compared to gold, which serves as a safe haven for investors to carry out risk portfolios [5]. Bitcoin is often seen as a panacea, replacing financial institutions, and providing shelter for sovereign risk and weakness in the global financial system [6], especially during the surge in the
Banking Crisis of Cyprus in 2012-2013 [5]. Importantly, the literature believes that Bitcoin has a very weak relationship with traditional assets, which makes it a valuable diversifier $[7,8]$ and in some cases a hedge or a safe haven against equities [6]. Excluding the asymmetric response in variance, Klein et al. [9] argue that cryptocurrencies are the same as gold in volatility, correlation, and portfolio performance, which makes it a probable alternative. With the increasingly close connection with other markets, its volatility has become a hot topic for scholars.

Investors' expectations for Bitcoin's risk aversion characteristics seem to be broken in the risk of contagion. Kyriazis et al. summarized the volatility and persistence of cryptocurrency bubbles using a literature review, revealing a strong confounding effect on its guidance on financial markets [10]. Fry and Cheah [11] used mathematical financial models to deduce that financial events strike based on the size and degree of BTC bubbles, even a negative bubble. The alternating surge of Bitcoin and Dogecoin proves this bubble effect. In contrast to stock indices, Cheah et al. [12] find that BTC builds speculative bubbles, affecting 
the extent to which it functions as a weak or strong safe haven. When the cryptocurrency market enters an uptrend, the rise in exchange rates actively increases the comovement of cryptocurrencies, thus limiting investors from taking advantage of diversification. Enoksen et al. [13] measured the bubble cycles of eight cryptocurrencies, verifying the rationality of cryptocurrencies surging at the beginning of 2018. They also determined that higher volatility, volume, and transactions are positively correlated with the bubbles between cryptocurrencies, which lay a possible explanation for dynamic in the cryptocurrency market. In 2020, COVID19 is prevalent, scholars pointed out that the epidemic caused the fluctuation of Bitcoin prices [14-16]. With the gradual dissipation of this major health incident, the relationship between macroeconomic events and the cryptocurrency market has attracted attention. Combining wavelet decomposition and Granger causality test, Li et al. [17] found time asymmetry in the causal relationship between the return of different cryptocurrencies and investors' attention. The combination of time and frequency has occupied this research field for a long time. Wavelet packet decomposition can handle dilemmas such as nonstationarity, nonlinearity, and especially periodic behaviors that vary at different frequencies [18]. Wavelets are used to produce an orthogonal decomposition of some economic variables by time scale over six timescales ranging from low to high frequency, which provides serious flexibility. The wavelet package offsets the drawbacks of wavelet decomposition and considers the lead-lag relationship at different time scales. Fruehwirt et al. [19] used wavelet-coherence analysis to measure intraday data (5-min resolution) to study the dynamic time-frequency conversion between cryptocurrencies. Using wavelet analysis, Celeste et al. [20] found that BTC behaves as a random walk to a greater extent, while the changes in other cryptocurrencies in different frequency domains have potential memory properties. Rhaeim et al. apply the wavelet decomposition method to get the more significant characteristics of the French stock market in the short and long term [21], while Fernandez concludes that the Chilean stock market is more suitable for the medium term [22]. The perspective of investors is heterogeneous, and the research is limited just basing on the period brought by frequencies. Risks and returns come together. While investors are looking for high returns, they must fully understand the possible influencing factors of the investment portfolio and reduce risks from the whole to the part. Therefore, it is necessary to study the multiscale systemic risk under the volatility of the cryptocurrency market.

The existing literature on the measurement of systemic risk and its risk contagion is insufficient. Many studies focus on the systemic risks of cryptocurrencies but discuss only linear and nonlinear models based on a one-dimensional perspective. Some cutting-edge studies analyze risks from a frequency-domain perspective, particularly frequency changes in very short periods. Only a few studies investigate the spillover network of cryptocurrencies and the interaction mechanism between different cryptocurrencies based on the breakpoint of the Markov transformation matrix. Our research offers several contributions to the literature. First, from the perspective of the theoretical framework of systemic risk, we provide feasible research ideas and improve the nonlinear research based on systemic risk. In the nonlinear stage, the STVAR model with embedded state variables was introduced, the changes within the regime were examined, and the current shortage of the Markov matrix used in the current stage was corrected, and the innovation of the research model from time to frequency to regime was achieved. Second, from the perspective of academic research, we use the cryptocurrency market index (CRIX) as a state variable to consider the influence under different regimes brought by the cryptocurrency market and also enlighten the possible directions of future research: introducing other macro variables closely related to the cryptocurrency market as state variables. At the same time, optimizing wavelet decomposition into wavelet packet decomposition is a generalized measure. Third, from the perspective of investors' risk portfolio, we propose appropriate portfolio strategies in terms of type and time.

The rest of the paper is organized as follows. The next section describes the recent emerging literature on cryptocurrencies and its research methods for systemic risk. The subsequent section describes the methodology and data, and we present the results of our empirical analysis thereafter. The final section draws the main conclusions.

\section{Literature Review}

We arrange the documents in three ways. First, we reported on the research on the relevance of the cryptocurrency market. Second, we compiled the current main metrics and their applications for systemic risk. Finally, we combed the methodological context of the multiscale systemic risk of cryptocurrency and made theoretical preparations for the expansion of nonlinear research.

There have been many attempts to study the relevance of cryptocurrencies using objects and models. Guesmi et al. [23] reported that the DCC-GARCH model is the best-fit model for the joint dynamics of different financial assets. Tu and Xue [24] investigated the effect of the bifurcation of BTC on its interaction with LTC with the BEKK-MGARCH model. Some scholars investigated the issue from the perspective of contagion. Notably, Corbet et al. [25] examined the relationships between BTC and a range of assets (i.e., oil and the S\&P500) and cryptocurrencies using Granger causality in the distribution. They found a significant bidirectional causal relationship between BTC and other assets that can also apply to mutual cryptocurrencies [26]. Recently, with the rapid development of cross-subjects, finance studies have functions between been trying to insert sociology into daily research to visualize the results. The use of network topology to explore the contagion of systemic risk gained much popularity, which may become the main form of data presentation. Diebold and Yilmaz (2014) proposed a representative study using network correlation models. Many scholars successfully employed the construction of mutual relations, which can help clarify stress periods (i.e., economic crises) and their propagation mechanisms and identify systemic risk [27]. Yi et al. [28] investigated both 
static and dynamic volatility connectedness among eight typical cryptocurrencies and found that their connectedness fluctuates cyclically. Beneki et al. [29] documented volatility transmission from ETH to BTC. By analyzing the volatility of cryptocurrencies, Kyriazis et al. [10] pointed out that BTC, $\mathrm{ETH}$, and XRP are the top three in the existing market, and the other cryptocurrencies combined still lagged after this group. Fassas et al. [30] focused on why newly launched future contracts contribute to the price discovery process of BTC. Their results demonstrated the strong bidirectional dependence in the intraday volatility of the BTC spot and futures markets. Different methods of correlation research have led to the different risk relationships between cryptocurrencies and the different status of BTC. From the perspective of investor risk aversion, it is necessary to make more accurate and detailed risk estimates for different cryptocurrencies.

"Systemic risk" pertains to risks of breakdown or major dysfunction in financial markets and its main metrics include value-at-risk (VaR), marginal expected shortfall (MES), systemic expected shortfall (SES), conditional valueat-risk (CoVaR), systemic risk measure (SRISK), and the catastrophic risk of financial firms (CATFIN). VAR refers to the maximum loss under a given risk level, but based on the need to detect tail dependence and extreme risks, CoVaR is often used to capture the missing links under VAR. At present, CoVaR model is the most widely used and expanded in the literature. In an empirical study, Selmi et al. [31] used the $\mathrm{CoVaR}$ indicator and found that a BTC-oil portfolio can reduce the effectiveness of overall risk for stability. Using vine (C-vine) copula and c-vine CoVaR, Uddin et al. [32] found a multiple tail dependence structure and risk spillover in the energy market. By combining CoVaR and SRISK indicators, Deming [33] found that bank failures are related to systemic risk. Feng et al. [34] measured the tail risk of a single cryptocurrency using an ARMA-GARCH model and the bivariate tail correlation between seven cryptocurrencies using a logistic function. Based on the measurement considerations of the systemic risk of the microcryptocurrencies market, we apply a CoVaR-GARCH model for the risk test of the rate of return together with the particular feather hidden in the series.

Initially, the research on systemic risk mainly focused on the CAPM model, which directly calculated the changes in systemic risk. Later, Hansen summarized the four analysis methods for systemic risk research at this stage from a static and dynamic perspective [35]: tail measures, contingent claims analysis, network models, and dynamic, stochastic macroeconomic models. Cortes et al. proposed complementary views on systemic risk assessment, connectivity functioning as the key Indicator [36]. Starting from the externalities of systemic risk, Acharya et al. introduce risk weighting factors into the model [37]. And Reichert continues to broaden, till the factor-copula framework, thus calculating systemic risks to mine risk exposures [38]. However, prior studies ignored the feature of frequency, especially the inside high and low frequency, which may bridge the gap in portfolio and risk management decisions; thus nonlinear research on risk deserved more attention. By applying nonlinear technology, Silva Filho et al. [39] measured the contagion risk and volatility shock transmission, as well as its evolution, concluding that a large decrease (or increase) in the price of one cryptocurrency would spill over to the price of the corresponding pair of cryptocurrencies, the BTC-pairs win matching with market capitalization. Kurka [40] argued that although Bitcoin seems isolated from other financial assets over their full sample period, market linkages arise when examining subperiods carefully. Manavi et al. [41] found a strong clustering of cryptocurrencies. The correlation values differ according to the coarse graining time, but not the clustering. Clusters exist for short time scales and are rather stable for the examined time intervals. Investors have long-term investment horizons reflected in short frequencies, whereas speculators have short-term trading horizons reflected in long frequencies [42]. Research on risk spillovers under different periods is a topic that has been extensively studied. Wavelet, with its ability to detect and locate volatility [43], and meanwhile transitioning the research from time to frequency, showed the property of risk changing with time $[44,45]$, which becomes a widely accepted tool of multiscale systemic risk research. The wavelet packet offsets the shortcomings of wavelet decomposition and considers the lead-lag relationship under different time scales. Keeping the elements of wavelet, we adopt optimized wavelet packet decomposition. Multiscale variance was developed by Percival [46] and used in finance field firstly by Ramsey and Lampart [47]. Ramsey and Lampart determined causality relation between consumption, GDP, income, and money by means of wavelet analysis. When market fluctuations are difficult to predict, the research and understanding of classical wavelet frequency domain methods are not enough to allow investors to make in-time decisions [48]. Using a vector autoregressive model based on quantiles, Bouri et al. point out that cryptocurrency has an asymmetric effect between the return and overflow behavior of the low quantile and the upper quantile, which also provides a nonlinear optimization for systemic risk opportunity. Bianchi et al. take the lead in using the Markov transition matrix to examine the impact mechanism of global bank index returns on macroeconomic state variables and bank holding company stock price returns. This makes the study of systemic risk take a big step, that is, to expand from the limitation in frequency to the study of external state variables [49]. Authors consider more macro variables or markets, such as stock market and public expenditure $[22,50,51]$. Under the new situation, Moratis proposed the use of a rolling window Bayesian vector autoregressive model measured the risk spillover of the cryptocurrency market and discovered the important role of external driving factors [52]. Based on the structural mutations brought about by the financial crisis, Zhou selected Sweden's 10-year industrial production index modeling, while Timo et al. selected 47 macrovariables of the G7 economy to test the effectiveness of the STVAR model and concluded that this STVAR model is better than the linear model [53, 54]. Venetis summarized the symmetric deviations in monetary policy to demonstrate the rationality of the STVAR model to allow multiple discontinuities [55]. Representing different 
market conditions by bull and bear markets, Das et al. examine the spillover effect of stock returns [56].

Therefore, we focus on the cyclical nature of the market index itself to explore the risk spillover effect between cryptocurrencies under different scales, which echoes the reality of the cryptocurrency market's skyrocketing and plummeting. The transition of different market conditions is slow, and there are more possibilities for research on the lag period in the future [56].

\section{Methodology and Data}

3.1. Wavelet Packet Transform. Wavelet analysis provides an effective method to decompose the time series in the time domain into the scale domain and locate the time changes in different scales [57-59]. In 2008, Aggarwal et al. [60] used wavelet transform to decompose historical price data into wavelet domain to form subsequences and then combined with other time domain variables to propose a prediction model. Wavelet packet transform is particularly suitable for predicting the trend of time series data, because wavelet can "decompose economic time series into time-scale components," which is a very successful strategy to untie the relationship between economic variables [61], and MATLAB software wavelet packet analysis can already be used maturely. Huang et al. [62] used the biorthogonal wavelet to construct the hybrid kernel function under the support vector machine (SVM) to predict the effective range of a possible financial crisis, and it was verified in the set of all listed companies. Using wavelet decomposition which accounts for the characteristics of low- and high-frequency data, Teng et al. [26] decomposed the high-frequency mode of the original stock price data but retained the low-frequency mode and found that it enhanced the predictability of stock sequences. Based on the significant impact of COVID-19 globally, Štifanić et al. [63] used the stationary wavelet transform (SWT) and bidirectional long short-term memory (BDLSTM) networks to achieve good predictions of crude oil prices and stock trends over the following five days.

The wavelet analysis approach includes two branches. One branch focuses on the wavelet transform (WT). The WT is suitable for addressing signals that are distorted under a strong noise background. It applies to the optimization of the log-return series in a fluctuating financial market. The WT adapts the signal to another domain in which richer information can be revealed in an easier way. With the characteristics of the wavelet basis function, the WT can be very effective for describing signals with sharp spikes and discontinuities [64]. The realization of WT can be divided into continuous WT and discrete WT. In the real world, we prefer discrete WT. Multilevel WT is called the "tree algorithm" to offer a hierarchical representation of signals, item by item.

The other branch centers on the application of the wavelet packet transform (WPT). As an extension of the WT, the WPT decomposes the signal layer by layer toward more detailed branches, enriching the tree structure. Through the WPT, several wavelet packet coefficients innervate a series of different frequencies, generating and discarding the residual signal in the parent wavelet, such as a filter [65]. The WPT grasps the characteristics in time and frequency domain features, intuitively representing signal information in the most suitable way. The WPT not only inherits the preponderances of the WT, as it strikes a balance between high- and low-frequency bands but also compensates for the drawbacks of the WT, specifically that it has difficulties adapting to higher frequency bands, which are better for information refinement. The wavelet packets are the combination or superposition of the parent waveform, which retain the orthogonality, smoothness, and localization properties of the parent waveform. Wavelet packet analysis can provide insights on the joint behavior of indices, not only along the sole dimension of time but also over different investment time scales or frequency periods, thus enabling us to study the various co-movements between cryptocurrencies [66].

The total layer of the WPT is defined as $L$. The formulas for the WPT are

$$
\begin{aligned}
& \mu_{2 n}^{L-1}(t)=\sum_{k} h_{k} \mu_{n}^{L}(t-k), \mu_{n}^{L}(t-k)=\mu_{n}^{L-1}(2 t-k), \\
& \mu_{2 n+1}^{L-1}(t)=\sum_{k} g_{k} \mu_{n}^{L}(t-k), \mu_{n}^{L}(t-k)=\mu_{n}^{L-1}(2 t-k) .
\end{aligned}
$$

After simplifying the formulas above, the final expressions are

$$
\begin{aligned}
\mu_{2 n}(t) & =\sum_{k} h_{k} \mu_{n}(2 t-k), \\
\mu_{2 n+1}(t) & =\sum_{k} g_{k} \mu_{n}(2 t-k), \\
h_{k}(x) & =\frac{x_{k}+x_{k+1}}{2}, \\
g_{k}(x) & =\frac{x_{k}-x_{k+1}}{2},
\end{aligned}
$$

where $\mu_{0}^{0}(t)$ is the father wavelet and $\mu_{0}^{1}(t)$ is the mother wavelet. The superscript denotes the decomposition series in which the layer of the wavelet packet is located, and the subscript denotes the position of the wavelet packet in its layer. $h_{k}$ and $g_{k}$ denote the low-pass filter and high-pass filter, respectively.

With the WPT, an important step is to select the appropriate wavelet function basis for signal decomposition. The Haar wavelet is the simplest and oldest wavelet transform. In 1992, Daubechies developed the frequency domain characteristics of the Haar wavelet. Therefore, we select dbN for frequency segmentation which can smooth the series better than other wavelets and increase the separability of the frequency domain to decompose cryptocurrency returns, which is the basis of our measure of multiscale cryptocurrencies' systemic risks. The length of the support interval in $\mathrm{dbN}$ is $2 N-1$.

3.2. Nonlinear Granger Causality Test. The traditional nonlinear causality test does not have nonlinear predictive ability due to its low power $[67,68]$. Therefore, this study 
adopts the nonparametric test (D-P test) of nonlinear causality developed by Diks and Panchenko [69] in order to explore more causal relationships between related variables [70]. Since this test is nonparametric, it has advantages over parametric causality methods. In the D-P test, since it does not allow the conditional distribution to change with the increase of the sample size, the problem of excessive rejection is prone to occur. In order to avoid it, we follow their idea $[16,71]$ and use the D-P test as a nonparametric test to capture the nonlinear causality of the fluctuation of the logarithmic return of each cryptocurrency. At the same time, Diks and Wolski [72] extended the bivariate DP test to multivariate cases and believed that the DP method for detecting Granger noncausality is very consistent and robust, such as the mean and variance under Granger mean and variance. Therefore, the adoption in this study is reasonable.

In Diks and Panchenko's test, the null hypothesis that $X_{t}$ does not Granger cause $Y_{t}$ is

$$
H_{0}: Y_{t+1}\left|\left(X_{t}^{l x} ; Y_{t}^{l y}\right) \sim Y_{t+1}\right| Y_{t}^{l y},
$$

where $X_{t}^{l x}=\left(X_{t-l x+1}, \ldots, X_{t}\right)$ and $Y_{t}^{l y}=\left(Y_{t-l y+1}, \ldots, Y_{t}\right)$ are the delay vectors and $l x$ and $l y$ denote the finite lag lengths of $X_{t}$ and $Y_{t}$, respectively. By assuming $l x=l y=1$ and $Z_{t}=Y_{t+1}$, we can obtain the joint probability density function $f_{X, Y, Z}(x, y, z)$ of $W_{t}=\left(X_{t}^{l x}, Y_{t}^{l y}, Z_{t}\right)$ as follows:

$$
\frac{f_{X, Y, Z}(x, y, z)}{f_{Y}(y)}=\frac{f_{X, Y}(x, y)}{f_{Y}(y)}=\frac{f_{Y, Z}(y, z)}{f_{Y}(y)} .
$$

Diks and Panchenko further show that the reformulated null hypothesis implies

$$
q \equiv E\left[f_{X, Y, Z}(x, y, z) f_{Y}(Y)-f_{X, Y}(X, Y) f_{Y, Z}(Y, Z)\right]=0 .
$$

Diks and Panchenko then let $\hat{f}_{w}\left(W_{i}\right)$ be a local density estimator of a $d_{w}$-variate vector $W$, $\widehat{f}_{w}\left(W_{i}\right)=\left(2 \varepsilon_{n}\right)^{-d_{w}}(n-1)^{-1} \sum_{j, j \neq i}^{w} I_{i j}^{W}$, where $I_{i j}^{W}=I\left(W_{i}-\right.$ $\left.W_{j}<\varepsilon_{n}\right)$ with $I(\cdot)$ being the indicator function and $\varepsilon_{n}$ the bandwidth. We set the bandwidth as 1, embedding the dimension as 2 . The test statistic is

$$
\begin{aligned}
T_{n}\left(\varepsilon_{n}\right)= & \frac{n-1}{n(n-2)} \cdot \sum_{i}\left(\hat{f}_{X, Y, Z}\left(X_{i}, Y_{i}, Z_{i}\right) \hat{f}_{Y}\left(Y_{i}\right)\right. \\
& \left.-\widehat{f}_{X, Y}\left(X_{i}, Y_{i}\right) \widehat{f}_{Y, Z}\left(Y_{i}, Z_{i}\right)\right) .
\end{aligned}
$$

In the statistic, $\varepsilon_{n}=C^{-\beta}(C>0, \beta \in((1 / 4),(1 / 3)))$ guarantees that it satisfies

$$
\sqrt{n} \frac{\left(T_{n}\left(\varepsilon_{n}-q\right)\right)}{S_{n}} \stackrel{D}{\longrightarrow} N(0,1),
$$

where $S_{n}$ is an estimator of the asymptotic variance of $T_{n}(\cdot)$.

3.3. Risk Spillover Network. Network analysis also plays an important role in measuring systemic risks, because this analysis can better model and predict the behavior of complex financial systems. It is worth mentioning that for the stability of the system as a whole, what is needed is a riskbased systemic approach; that is, the systemic risk is used as the original data. In addition, when assessing systemic risks, it is very important to consider different measurement methods, because there is no perfect way to reflect the impact of interruptions on the entire system [73]. When the losses of one asset increase or volatility intensifies, it will have an excess impact on other assets, thus forming risk spillover. Hence, we apply the typical network topology method proposed by Diebold and Yilmaz [74] which is the prototypes of many other network analyses. We construct the following risk spillover matrix based on forecast-error-variance decompositions demonstrating the definition of this matrix as shown in Table 1.

In the spillover matrix in the table, the variables in the first row represent the source of risk spillovers and the vectors in the first column denote the entity receiving the risk. We can calculate the degree of pairwise risk spillover based on the following decomposition:

$$
S_{i \leftarrow j}^{H}=\frac{\sum_{h=0}^{H-1} a_{i j, h}^{2}}{\sum_{h=0}^{H-1} \operatorname{trace}\left(A_{h} A_{h}^{\prime}\right)},
$$

where $\sum_{h=0}^{H-1} a_{i j, h}^{2}$ is the error variance of the risk in cryptocurrency $i$ in forecast period $H$ caused by the impact of risk in cryptocurrency $j$ and $\sum_{h=0}^{H-1} \operatorname{trace}\left(A_{h} A_{h}^{\prime}\right)$ represents total forecast-error variance in period $H$. Therefore, the above exhibits the proportion of single cryptocurrencies. In general, $S_{i \leftarrow j}^{H} \neq S_{j \leftarrow i}^{H}$; we can define the effect of the net risk spillovers from cryptocurrency $j$ to cryptocurrency $i$ using the following formula:

$$
\mathrm{NS}_{i \leftarrow j}^{H}=S_{i \leftarrow j}^{H}-S_{j \leftarrow i}^{H} .
$$

Moreover, the items in the OUT row denote the total items on the nondiagonal lines in each column, allowing us to measure the spillovers from cryptocurrency $j$ to other cryptocurrencies. The IN column and the total net effect are similar:

$$
\begin{aligned}
\mathrm{TS}_{\mathrm{OUT}, \leftarrow j}^{H} & =\sum_{i} S_{i \leftarrow j}^{H}, \quad \text { for } i \neq j, \\
\mathrm{TS}_{\mathrm{IN}, i \leftarrow .}^{H} & =\sum_{i} S_{i \leftarrow j}^{H}, \quad \text { for } i \neq j, \\
\mathrm{NTS}_{i}^{H} & =\mathrm{TS}_{\mathrm{OUT}, \leftarrow j}^{H}-\mathrm{TS}_{\mathrm{IN}, i \leftarrow .}^{H}=\sum_{i} \mathrm{NS}_{j \leftarrow i}^{H} .
\end{aligned}
$$

In addition, we can measure the overall system-wide total spillover effectively by summing and taking the average of the items in the OUT row or the IN column, as follows:

$$
\begin{array}{r}
\mathrm{STS}_{i}^{H}=\frac{1}{N} \sum_{i} \mathrm{TS}_{\mathrm{IN}, i \leftarrow .}^{H}=\frac{1}{N} \sum \mathrm{TS}_{\mathrm{OUT}, \leftarrow j}^{H}=\frac{1}{N} \sum_{i} \sum_{j} S_{j \leftarrow i}^{H}, \\
\text { for } i \neq j .
\end{array}
$$

3.4. Smooth-Transition Vector Autoregression (STVAR). In order to characterize the nonlinear relationship of economic variables in different state intervals, Sims [75] made a 
TABLE 1: Definition of risk spillover networks.

\begin{tabular}{|c|c|c|c|c|c|}
\hline & $\Delta I V_{1}$ & $\Delta I V_{2}$ & $\ldots$ & $\Delta I V_{n}$ & IN \\
\hline$\Delta I V_{1}$ & $S_{1 \leftarrow 1}^{H}$ & $S_{1 \leftarrow 2}^{H}$ & $\ldots$ & $S_{1 \leftarrow n}^{H}$ & $\sum_{i} S_{1 \leftarrow j}^{H}, j \neq 1$ \\
\hline$\Delta I V_{2}$ & $S_{2 \leftarrow 1}^{1 \leftarrow 1}$ & $S_{2 \leftarrow 2}^{1 \leftarrow 2}$ & $\cdots$ & $S_{2 \leftarrow n}^{1 \leftarrow n}$ & $\sum_{i} S_{2 \leftarrow j}^{H}, j \neq 1$ \\
\hline$\cdots$ & $\ldots$ & $\ldots$ & $\cdots$ & $S^{H}$ & $\sum S^{H}{ }^{\cdots} j \neq 1$ \\
\hline $\begin{array}{l}\Delta I V_{n} \\
\text { OUT }\end{array}$ & $\sum_{i} S_{i \leftarrow 1}^{H \leftarrow 1}, i \neq 1$ & $\sum_{i} S_{i \leftarrow 2}^{H}, i \neq 2$ & $\begin{array}{l}\cdots \\
\cdots\end{array}$ & $\sum_{i} S_{i \leftarrow n}^{S_{n \leftarrow n}^{H}, i \neq n}$ & $\begin{array}{c}\sum_{i} S_{n \leftarrow j}^{i+j}, j \neq 1 \\
(1 / N) \sum_{i} S_{i \leftarrow j}^{H}, i \neq j\end{array}$ \\
\hline
\end{tabular}

pioneering exploration of vector autoregressive models and then developed a series of nonlinear VAR models. Among them, Markov-Switching Vector Autoregression (MSVAR), Threshold Vector Autoregression (TVAR), and SmoothTransition Vector Autoregression (STVAR) are widely used. In the STVAR model, the state variables that drive interval transitions are preset observable variables and support continuous transition mechanisms, which have strong explanatory power for the economy. Within the framework of the STVAR model, according to the different settings of the conversion function, it can be subdivided into Logistic Smooth-Transition Vector Autoregression (LSTVAR) model and Exponential Smooth-Transition Vector Autoregression (ESTVAR) model. The former can describe the high state variable interval and the low state variable interval. The asymmetry mechanism of the state variable interval and the ESTVAR model is mainly used to reflect the transition of the symmetric interval [76].

In order to examine the asymmetric contagion mechanism of CRIX on the cryptocurrency market, we refer to the research of Caggiano et al. [77], thus establishing the following model:

$$
\begin{aligned}
Y_{t}=\left[1-F\left(z_{t-1}\right)\right] & {\left[\prod_{b}^{p} Y_{t-1}+F\left(z_{t-1}\right) \prod_{g}^{p} Y_{t-1}+\varepsilon_{t}\right], } \\
\varepsilon_{t} & \sim N(0, \Omega),
\end{aligned}
$$

$$
\begin{aligned}
F\left(z_{t}\right) & =\left\{1+\exp \left[-\gamma\left(z_{t}-c\right)\right]\right\}^{-1}, \\
\gamma>0, E\left(z_{t}\right) & =0, \operatorname{Var}\left(z_{t}\right)=1,
\end{aligned}
$$

where $Y_{t}$ represents a set of endogenous variables that are partly selected from the cryptocurrency market. $F\left(z_{t}\right)$ is a logistic transition function which is used to describe the probability of the sample being divided into different "economic state" (recession and expansion at CRIX). The nonnegative parameter $\gamma$ determines the rapidity of the switch from a regime to another (the higher $\gamma$, the faster the switch), and $z_{t}$ is a state variable used to capture the periods of CRIX. $c$ is the threshold parameter identifying the two regimes. $\prod_{b}^{p} Y_{t}$ and $\prod_{g}^{p} Y_{t}$ indicate the coefficient matrix of CRIX in two regimes, and $\varepsilon_{t}$ is the vector of reduced-form residuals obeying a normal distribution.

In function (12), $Y_{t}$ is the endogenous variables of STVAR model including state variable and CoVaR of each cryptocurrency at specific period which represents for Bitcoin (BTC), Tether (USDT), Stellar (XLM), Ethereum (ETH), Binance Coin (BNB), NEM (XEM), Litecoin (LTC), XRP (XRP), EOS (EOS), Dash (DASH), Monero (XMR), Bitcoin Cash (BCH), Dogecoin (DOGE), VeChain (VET), Chainlink (LINK), and THETA (THETA). $z_{t}$ is the state variable processed by filtering and the parameters are with maximum likelihood and

$$
Y_{t}=\left[\begin{array}{c}
z_{t}, \mathrm{BTC}_{t}, \mathrm{USDT}_{t}, \mathrm{XLM}_{t}, \mathrm{ETH}_{t}, \mathrm{BNB}_{t}, \mathrm{XEM}_{t}, \mathrm{LTC}_{t}, \mathrm{XRP}_{t}, \mathrm{EOS}_{t}, \mathrm{DASH}_{t}, \mathrm{XMR}_{t}, \mathrm{BCH}_{t}, \mathrm{DOGE}_{t}, \mathrm{VET}_{t}, \\
\mathrm{LINK}_{t}, \mathrm{THETA}_{t} .
\end{array}\right]
$$

3.5. Data. In the selection of cryptocurrency, in order to make it better reflect the market, we set the total market share at $80 \%$ to select the number of cryptocurrencies. As discovered by Ciaian et al., when the market size and price changes are taken into account, there is a dependency between BTC and other currencies [78]. When it is expected that part of the cryptocurrency represents the entire market, the dominant currency and other currencies should be included $[16,79]$. At the same time, based on the need to calculate the systemic risk for the return rate sequence, we will consider the daily price (below 0.1 will make the result rather smaller and easy to bias the result) That is, first consider the market value and second consider the price. At the same time, considering as much as available data, we ignore currencies that have been listed too late or have already been delisted. Therefore, we have selected the above
16 cryptocurrencies in investing website and determined the sample interval ranging from February 8th, 2018, to April 11th, 2021. There are a total of 1159 observation days data, which makes it easier to estimate the relationship between risk and return [80]. Table 2 shows the respective prices of 16 cryptocurrencies arranged by market value. We chose the CRIX index following the Laspeyres construction and obtained the data from http://thecrix.de/.

\section{Empirical Results}

In this paper, the systemic risk value under wavelet packet decomposition is the main data of the follow-up research. First, based on the selected 1159 observations, calculate the logarithmic rate of return of these 16 cryptocurrencies, using the cryptocurrency market index CRIX as the state variable, 
TABLE 2: The dominance of 16 cryptocurrencies.

\begin{tabular}{lcc}
\hline Name & Dominance $(\%)$ & Price \\
\hline BTC & 51.76 & $\$ 58277$ \\
ETH & 12.28 & $\$ 2210.15$ \\
BNB & 3.67 & $\$ 497.21$ \\
XRP & 3.16 & $\$ 1.44728$ \\
USDT & 2.27 & $\$ 0.997$ \\
DOGE & 1.76 & $\$ 0.279866$ \\
LTC & 0.9 & $\$ 277.494$ \\
BCH & 0.84 & $\$ 941.27$ \\
LINK & 0.75 & $\$ 37.41$ \\
VET & 0.67 & $\$ 0.212868$ \\
XLM & 0.62 & $\$ 0.56744$ \\
THETA & 0.60 & $\$ 12.6065$ \\
EOS & 0.34 & $\$ 7.4078$ \\
XMR & 0.28 & $\$ 335.046$ \\
XEM & 0.18 & $\$ 0.42454$ \\
DASH & 0.16 & $\$ 329.25$ \\
\hline
\end{tabular}

The above ranking ends on April 11, 2021, and all data comes from investing website.

and then use wavelet packet decomposition to obtain 8 frequencies under the two-level tree branch. With the combination of single rate of return and the market index combination, it is denoted as D8, D7, D6, D5, D4, D3, D2, D1, which express the frequency from $2^{j}$ to $2^{j+1}$, representing $2-4,4-8,8-16,16-32,32-64,64-128,128-256$, and 256-512 days $[43,81]$. Then, using the COVAR-GARCH model (Xu et al. discussed that this method is effective) [82], the systemic risk of 16 cryptocurrencies at 8 frequencies are obtained which is basic data in the DY matrix and STVAR models, and the one of nonlinear Granger causality test is the logarithmic rate of return.

4.1. Nonlinear Granger Causality Test Based on WPT. First, we use nonlinear Granger causality test to make a preliminary judgment on the causal relationship between cryptocurrencies. It has two functions. One is to visually demonstrate the effectiveness of wavelet packet decomposition and to verify that the previous frequency analysis results of systemic risks are reliable. The other is to take a single cryptocurrency as the center, look at its impact under different frequencies, and provide a control group for subsequent determination of frequencies that need to be focused on under different methods.

Table 3 shows the nonlinear Granger causality test between cryptocurrencies under the original sequence. We set the parameters which embeds dimension at 2 and bandwidth at 1 to calculate the causality. The table values are arranged horizontally, taking BTC for instance, and the causal relationship between BTC and other currencies is in the second row, and so on. Due to space limitations, the original data at other frequencies are available on request. We show it in the form of the heatmap. In the heatmap, the darker the color (red), the more significant the causal relationship, and the lighter the color (blue), the less significant the causal relationship. Figures 1-9, respectively, represent the original sequence and the causal relationship at different frequencies.
It can be found that under the wavelet packet decomposition, the causal relationship between cryptocurrencies is indeed different from that under the original sequence. Figures 2-6 are more red in the overall picture, while Figures 7-9 are mostly blue, representing the long-term and medium-term and short-term, respectively. At the same time, it can be seen that the long-term gradual change to red is represented in Figures 2-4, there was a gradual change to blue in the short term in Figures 7-9, in the medium term shown in Figures 5 and 6, we have two extreme colors, nearly wholly red or blue, and the medium term may be the key to change.

In view of the multiple surges of Bitcoin from 2018 to 2020, and the first surge of Dogecoin in April 2021, it is particularly important to analyze the causality of a single cryptocurrency at different frequencies, as shown in Figures 10-25, respectively. These 16 graphs show the nonlinear relationship between market value and risk, which fits the previous conclusions. We can see that D8 rows in these graphs are more or less blue, even for BTC, which occupies the top market. At any frequencies, the three cryptocurrencies (BTC, ETH, and XRP) occupying the main market capitalization are almost completely red, that is, the same strong risk causality for different currencies at different frequencies. However, in currencies with a relatively small market value, there is also a strong causal relationship at certain frequency, such as EOS, XMR, and DASH. It can be seen that for the risk contagion of cryptocurrency, the dominant cryptocurrency, and altcoins also play an important role, but the conversion relationship among them seems a little vague, and further analysis is needed, which provides the possibility for the analysis of the risk contagion path of the network. In connection with the multiple surges of Dogecoin in April, the causality diagram (Figure 22) shows a little trace, that only under D1 the red line appears, and the rest are blue. This also provides problem orientation for expanding systemic risks under time and frequency.

4.2. Risk Spillover Matrix (DY Matrix) Based on WPT. First, based on the SC criterion, the optimal lag order for the VAR basic model is determined to be 2. After the COVARGARCH model is estimated, the "disturbance correlation coefficient matrix" (DY matrix) between each cryptocurrency can be obtained, as shown in Tables 4 and 5. We choose D1 and D8 to display, and the results at other frequencies are available on request. As Tan and Pedersen said, the combination of wavelet packet decomposition and network analysis will greatly improve data performance [68]. Taking Table 4 as an example, the values at the edges of the matrix are, respectively, total values, expressing the horizontal or vertical value of a certain cryptocurrency. The "TO" column indicates the spillover risk of a certain currency against other currencies in the market, which is an arrow to go out, and the "FROM" column indicates that from the perspective of the total market size, to measure the spillover risk of other cryptocurrencies for a certain currency, it is an arrow of entry, which corresponds to the network below, so that the value in the middle of the matrix 


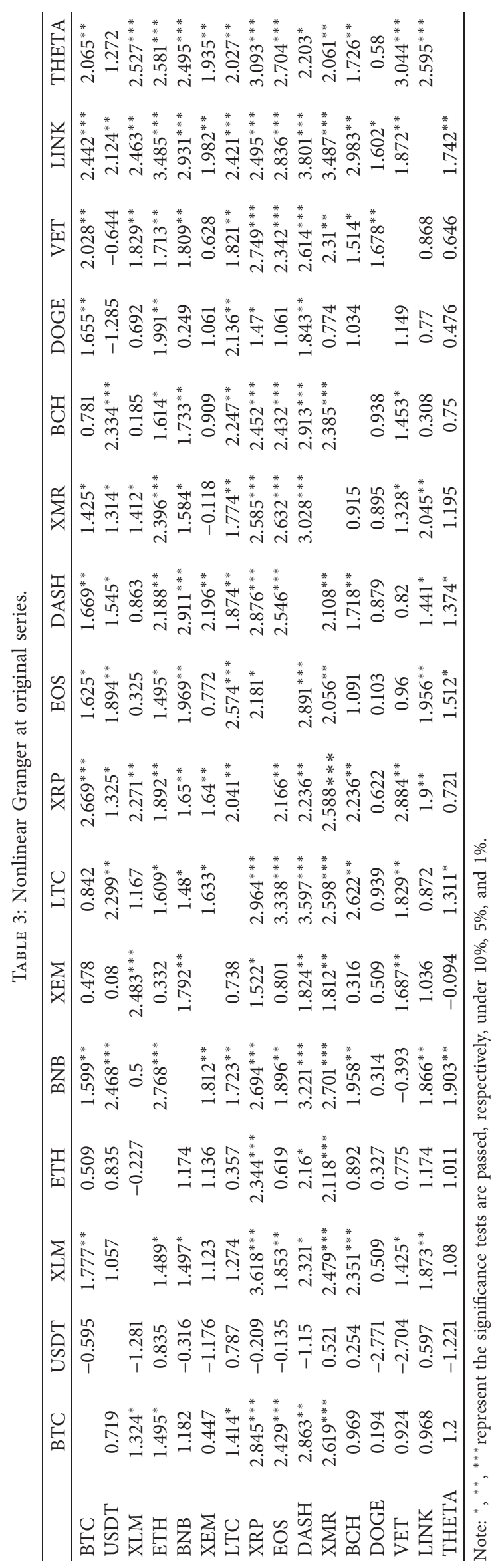




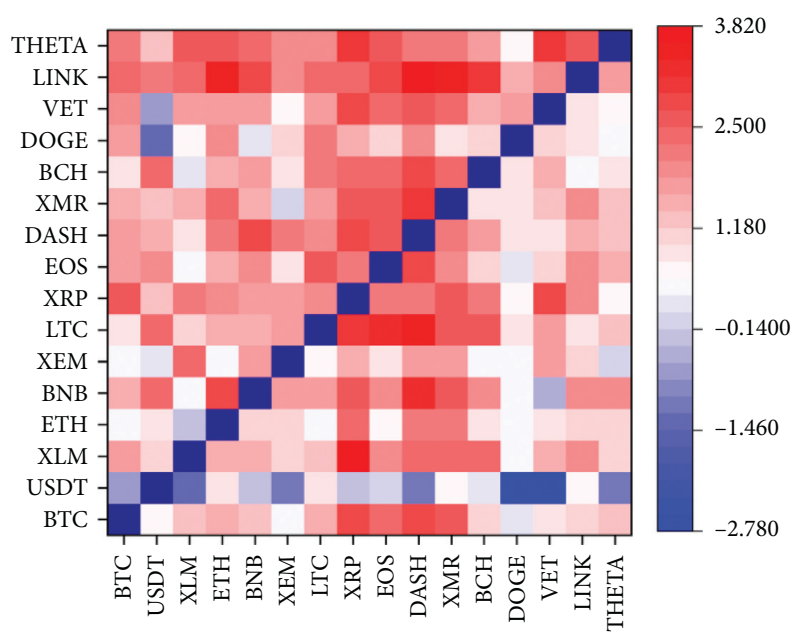

FIgure 1: Causality test under Original series9 (D0).

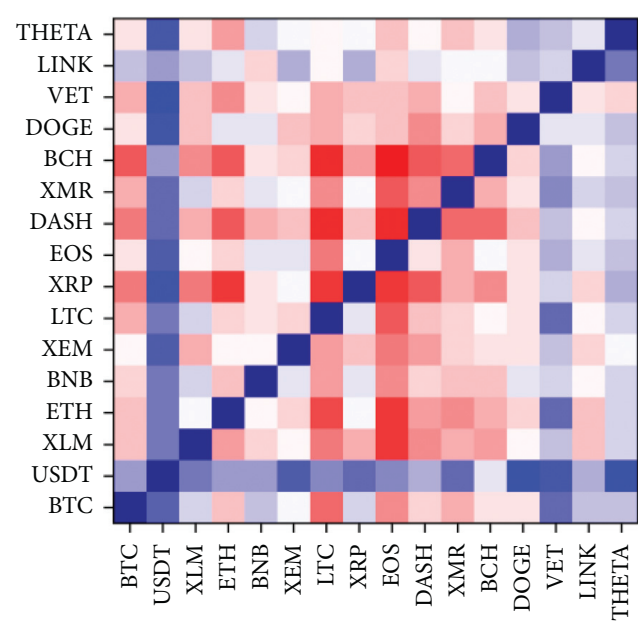

Figure 2: Causality test under D1.

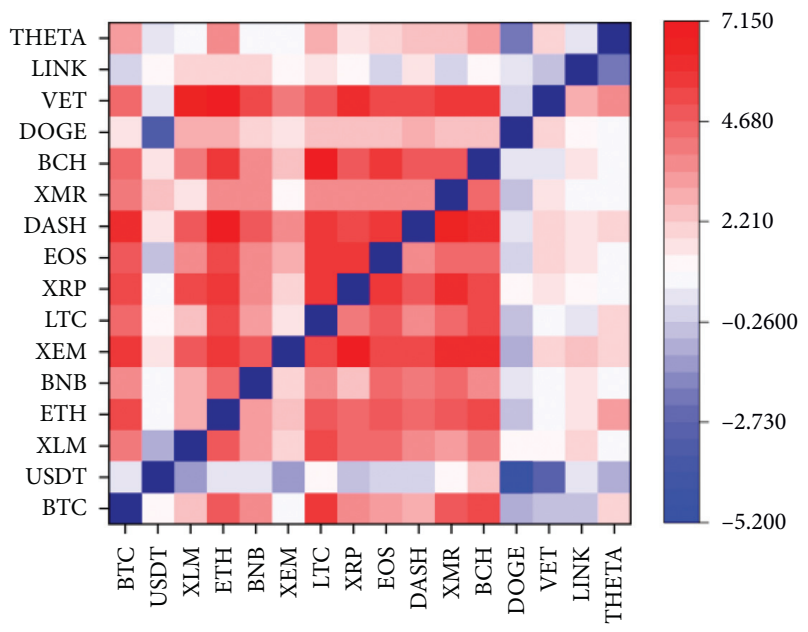

FIgUre 3: Causality test under D2.

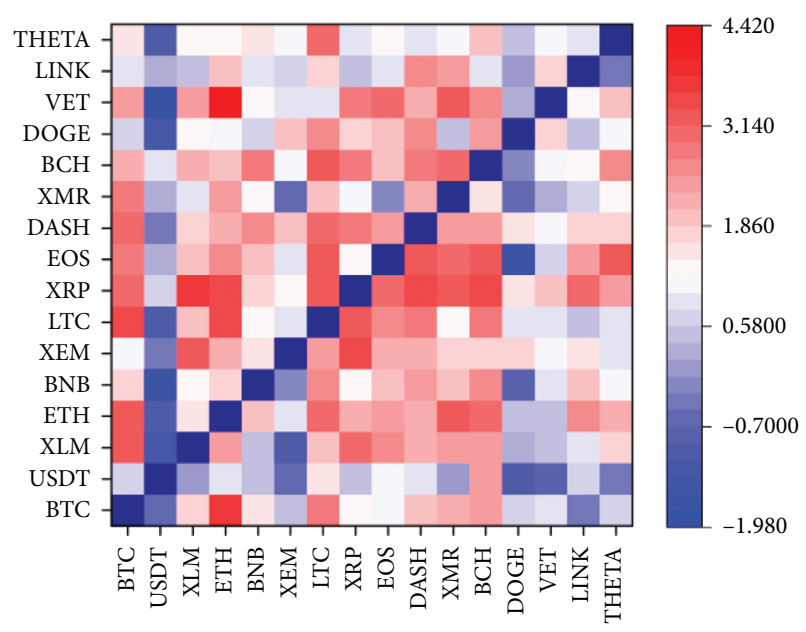

Figure 4: Causality test under D3.

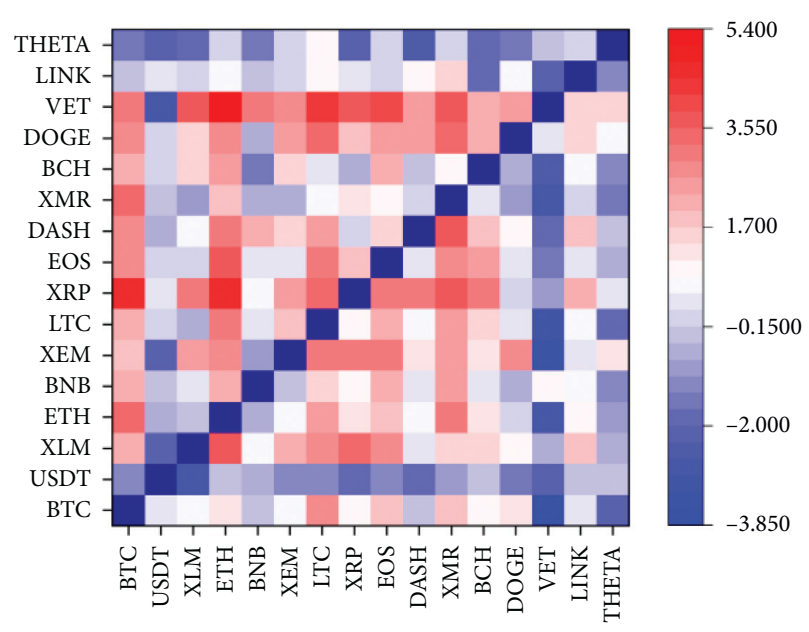

Figure 5: Causality test under D4.

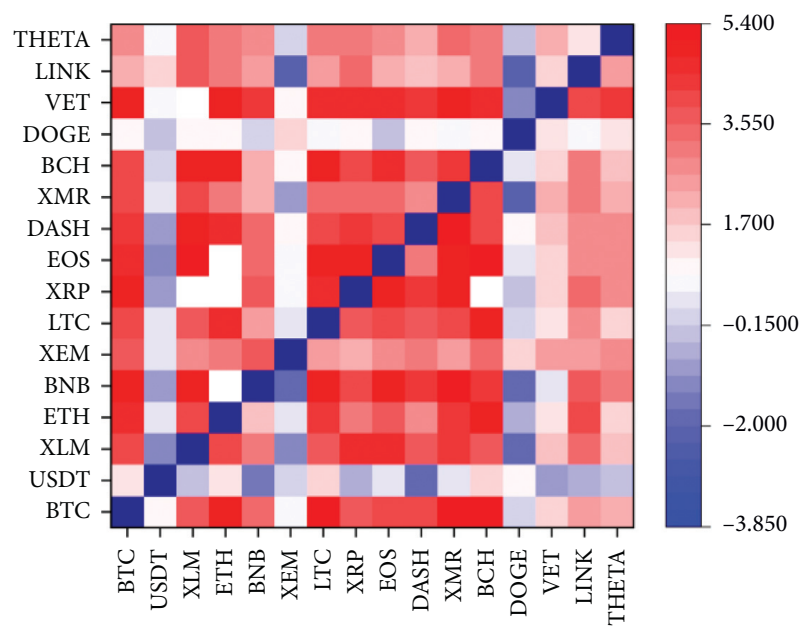

Figure 6: Causality test under D5. 


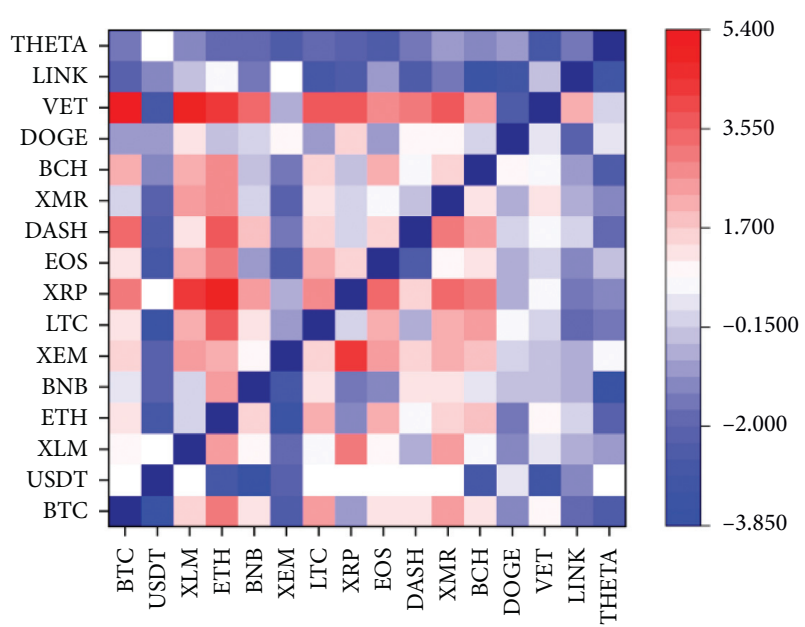

Figure 7: Causality test under D6.

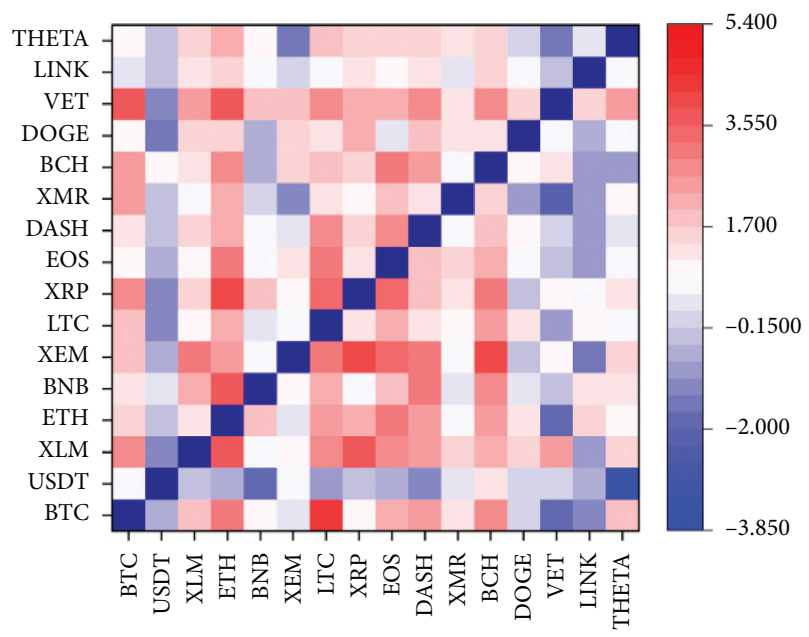

Figure 8: Causality test under D7.

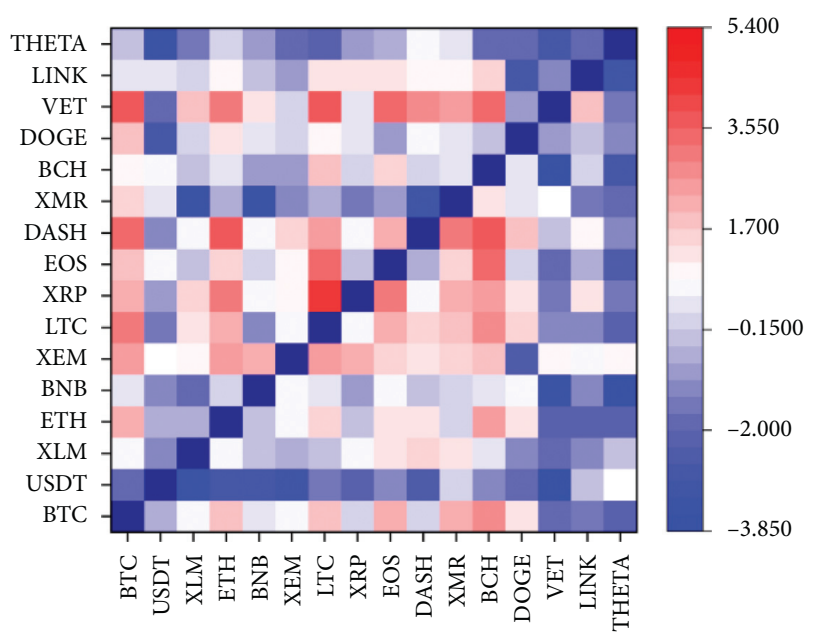

FIgure 9: Causality test under D8.

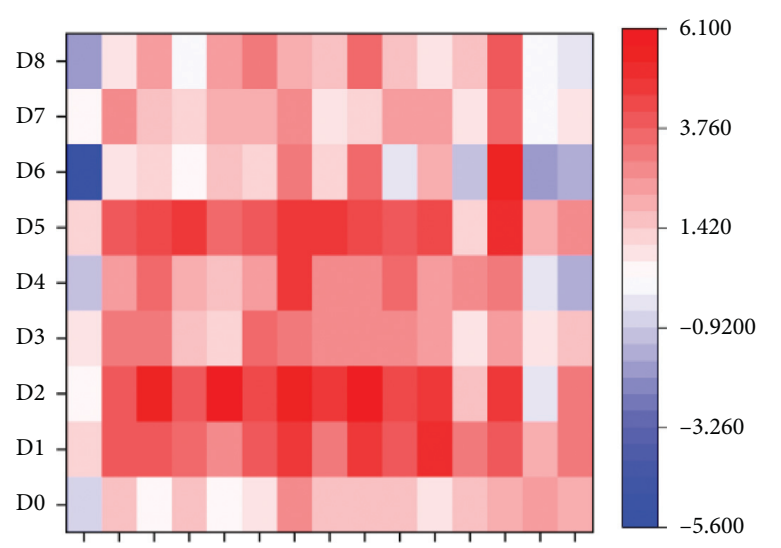

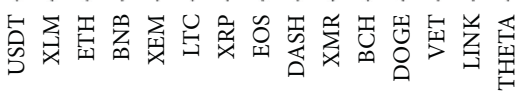

Figure 10: BTC to the other.

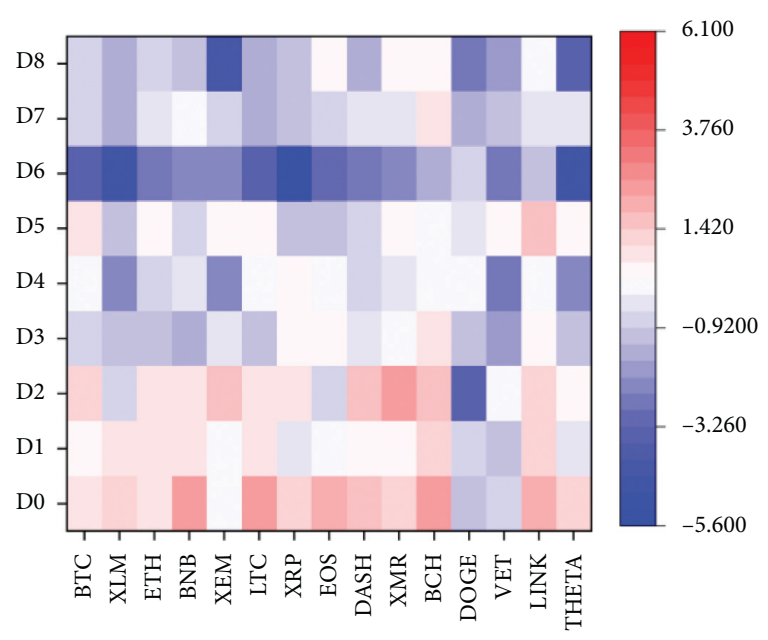

FIGURE 11: USDT to the other.

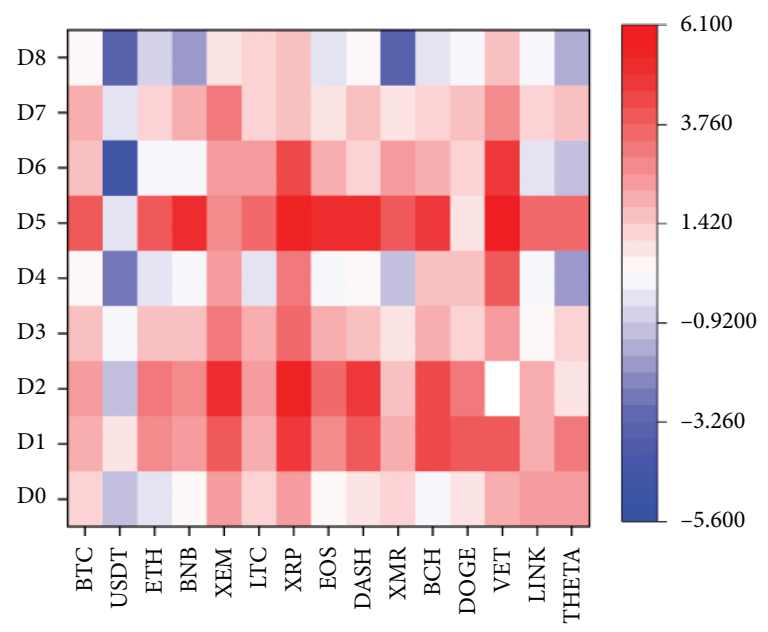

Figure 12: XLM to the other. 


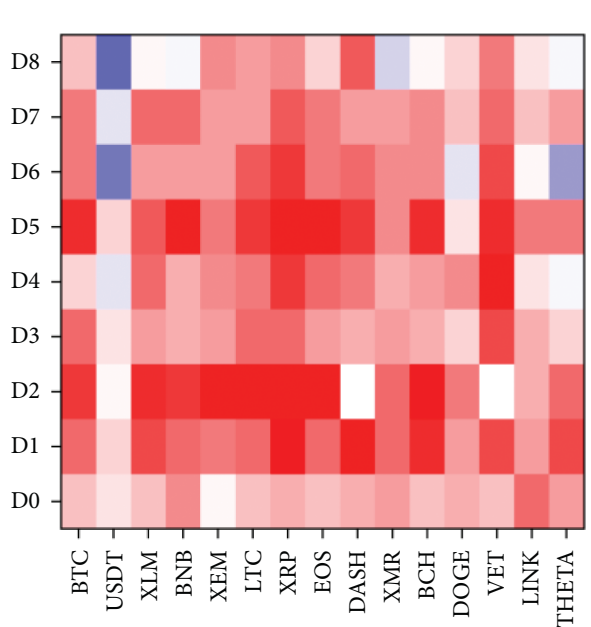

Figure 13: ETH to the other.

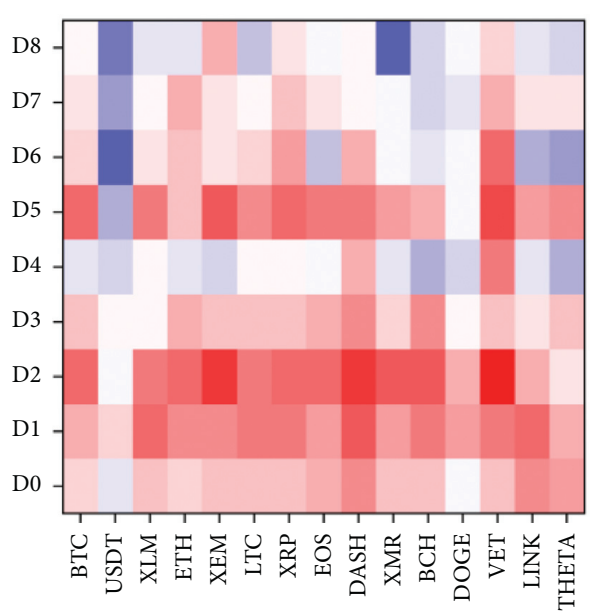

FIgURE 14: BNB to the other.

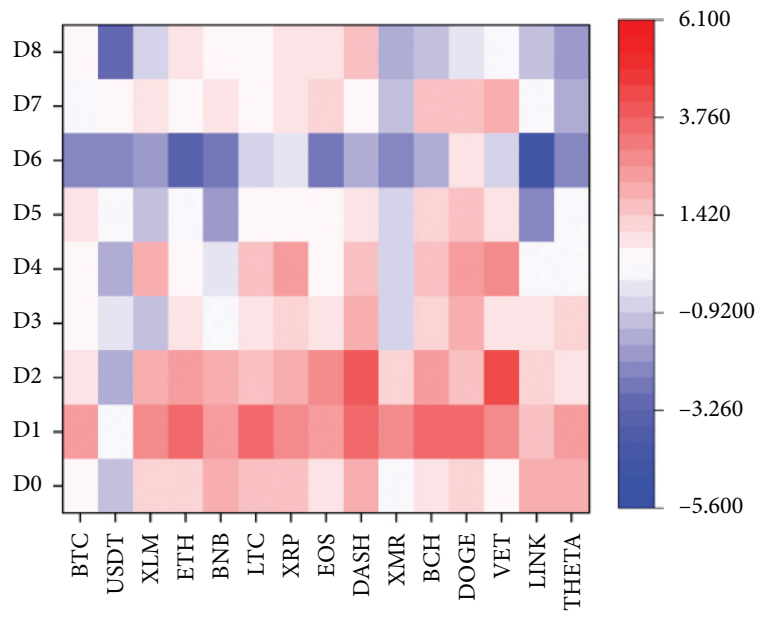

Figure 15: XEM to the other.

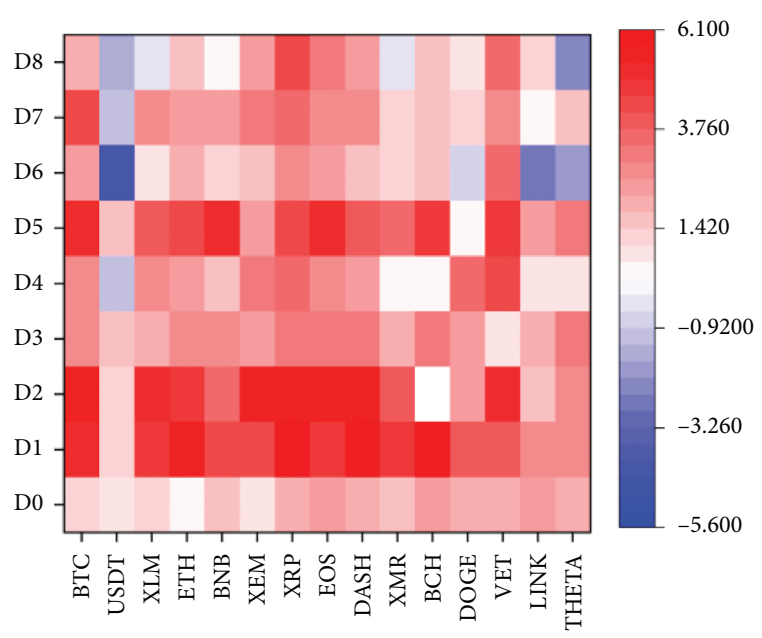

Figure 16: LTC to the other.

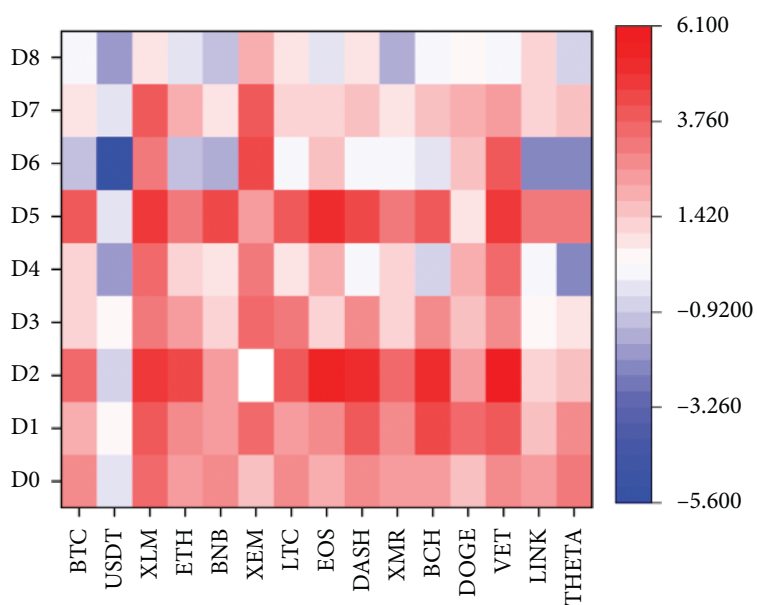

FIgURE 17: XRP to the other.

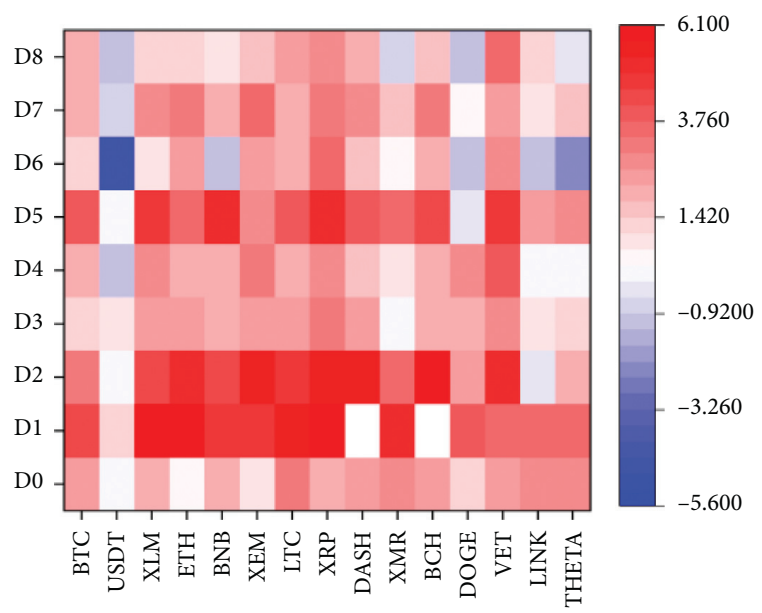

Figure 18: EOS to the other. 


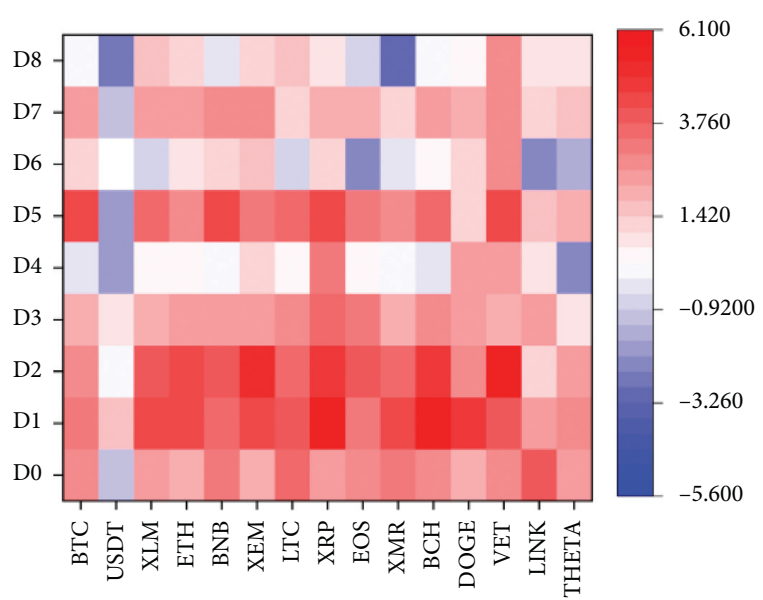

FIgURE 19: DASH to the other.

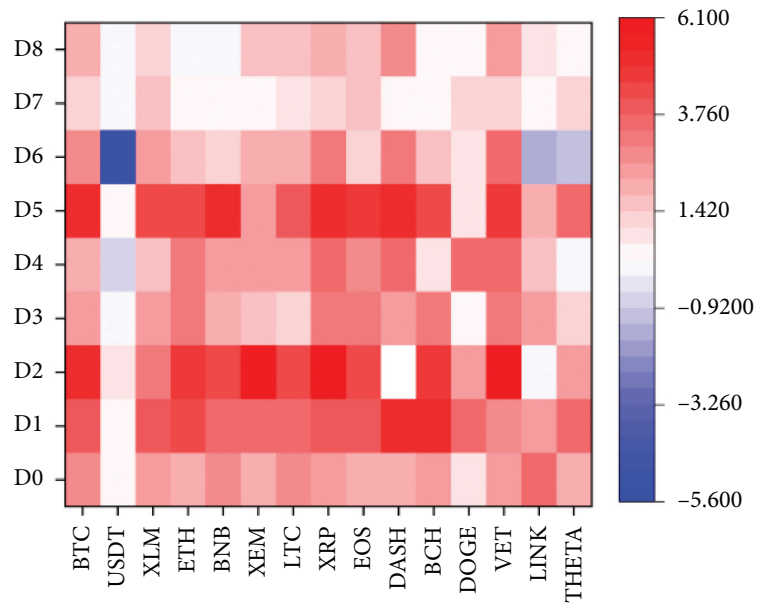

Figure 20: XMR to the other.

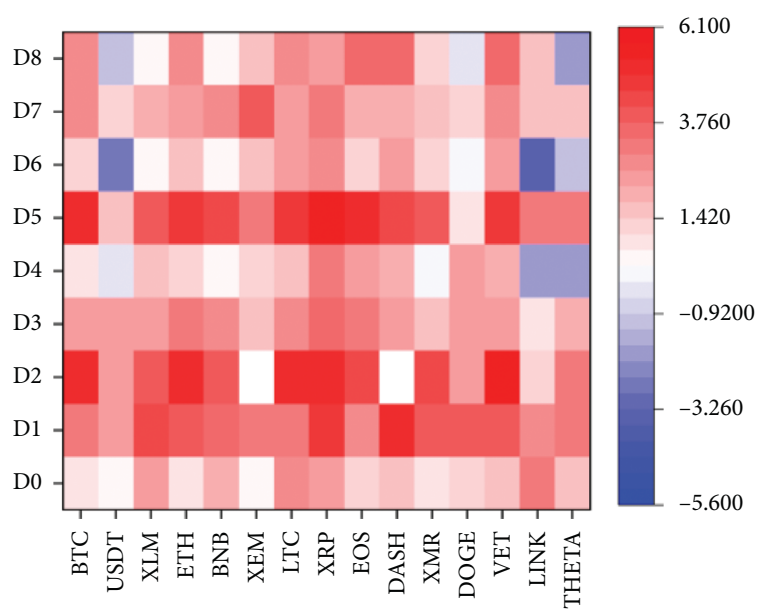

Figure 21: $\mathrm{BCH}$ to the other.

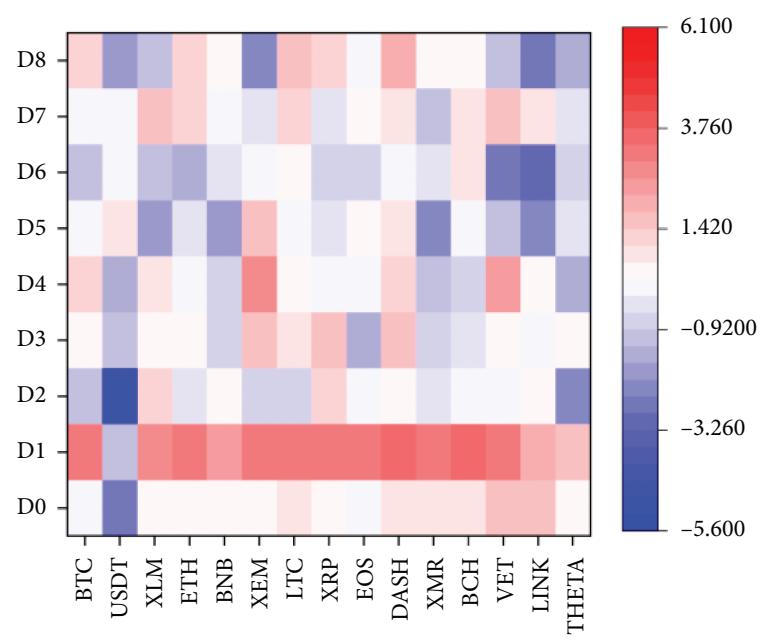

Figure 22: DOGE to the other.

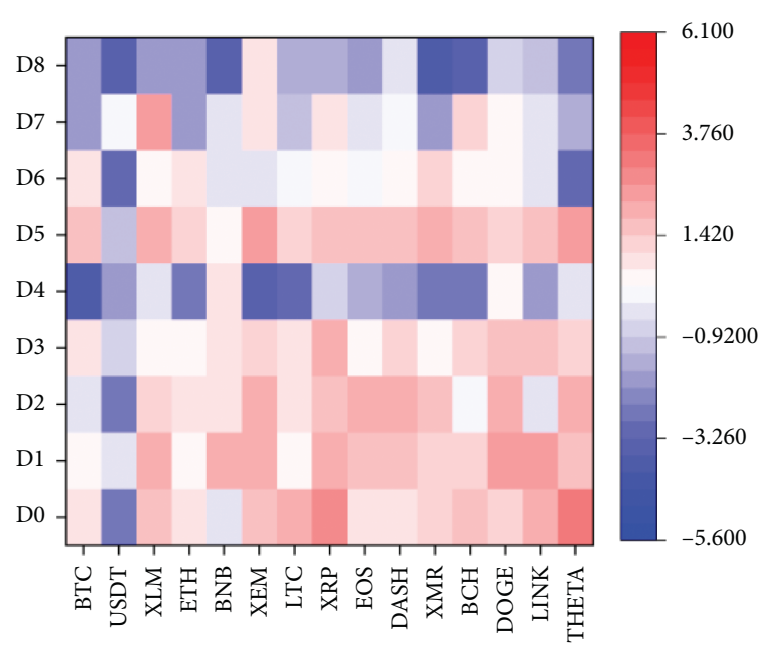

Figure 23: VET to the other.

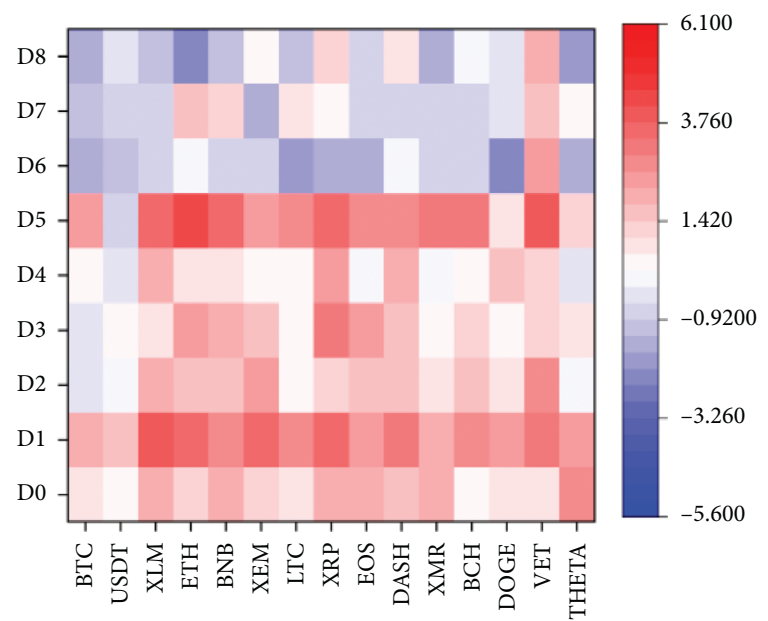

Figure 24: LINK to the other. 


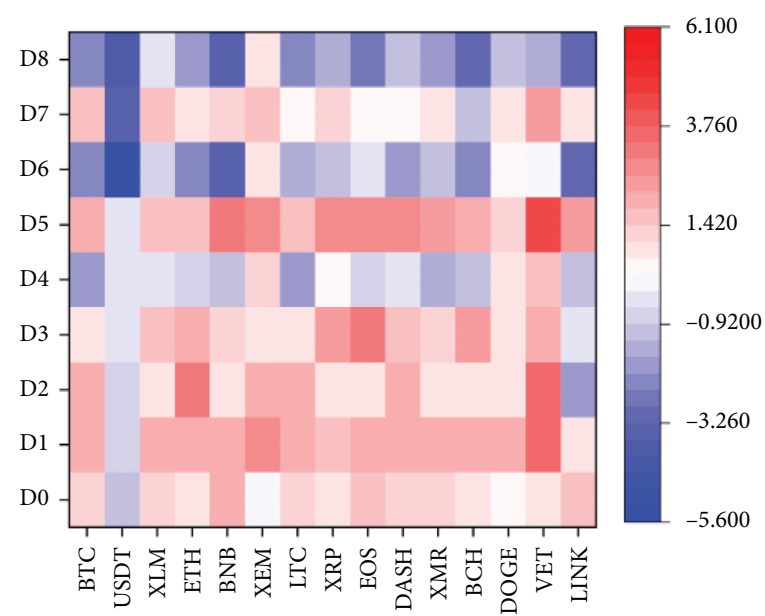

Figure 25: THETA to the other.

Table 4: DY index under D1.

\begin{tabular}{|c|c|c|c|c|c|c|c|c|c|c|c|c|c|c|c|c|c|}
\hline & BTC & USDT & XLM & ETH & BNB & XEM & LTC & XRP & EOS & DASH & XMR & $\mathrm{BCH}$ & DOGE & VET & LINK & THETA & FROM \\
\hline BTC & 45.2 & 4.1 & 13.9 & 8.1 & 5.5 & 6.4 & 2.3 & 1 & 0.9 & 0.6 & 2.1 & 3.4 & 1.4 & 1.7 & 0.3 & 3 & 54.8 \\
\hline USDT & 2.5 & 59.7 & 5.6 & 5.8 & 2.8 & 1.8 & 1.8 & 2.2 & 0.4 & 0.5 & 1.7 & 1.1 & 1 & 5.6 & 0.3 & 7.3 & 40.3 \\
\hline XLM & 18 & 4.1 & 35.4 & 7.2 & 6.6 & 8.2 & 3.5 & 2 & 2.7 & 1 & 3.2 & 1.6 & 1.1 & 1.8 & 1.9 & 1.7 & 64.6 \\
\hline ETH & 21 & 4.3 & 17.3 & 20.3 & 8.1 & 7.6 & 2.7 & 1.2 & 2.8 & 1.1 & 3.4 & 2 & 1.6 & 2.2 & 1.1 & 3.1 & 79.7 \\
\hline $\mathrm{BNB}$ & 13.9 & 3.8 & 13.5 & 10 & 35.9 & 9.8 & 2.5 & 0.3 & 1.4 & 0.4 & 3.4 & 1.6 & 0.7 & 0.5 & 0.9 & 1.4 & 64.1 \\
\hline XEM & 14.4 & 2.7 & 20.5 & 8.4 & 5.5 & 32.2 & 2 & 2 & 1.3 & 2.2 & 2.7 & 0.3 & 1.3 & 0.5 & 1.3 & 2.7 & 67.8 \\
\hline LTC & 19 & 4.8 & 24.1 & 9.5 & 7.6 & 7.8 & 11.8 & 1.3 & 2.4 & 1 & 2.6 & 2 & 1 & 2.1 & 1 & 1.9 & 88.2 \\
\hline XRP & 15.5 & 3.2 & 24 & 9 & 6.5 & 8.9 & 4.4 & 14.4 & 1.7 & 0.8 & 3.7 & 1.5 & 2.2 & 1.1 & 1.1 & 1.8 & 85.6 \\
\hline EOS & 17.9 & 3.8 & 22.1 & 10.4 & 8.3 & 8.4 & 5.4 & 1.6 & 9.1 & 0.9 & 3.5 & 2 & 1 & 1.8 & 1.2 & 2.6 & 90.9 \\
\hline DASH & 18.5 & 3.5 & 20.9 & 12.4 & 7.1 & 8.2 & 2 & 1.9 & 2.8 & 10.3 & 3.8 & 1.1 & 1.8 & 1.1 & 1.2 & 3.4 & 89.7 \\
\hline XMR & 18.1 & 4.6 & 21.1 & 9.3 & 8.3 & 7.6 & 2.7 & 2 & 2.7 & 2.6 & 13.1 & 1.6 & 1.3 & 0.9 & 0.8 & 3.3 & 86.9 \\
\hline $\mathrm{BCH}$ & 20.6 & 3.1 & 20.3 & 12.8 & 8.3 & 7.9 & 3.7 & 1.5 & 2.4 & 2.4 & 3.4 & 8.1 & 1 & 1.6 & 0.4 & 2.6 & 91.9 \\
\hline DOGE & 18.8 & 3.8 & 16.2 & 14 & 6.7 & 7.5 & 3.5 & 1.2 & 1.1 & 0.6 & 3.9 & 3 & 15.6 & 1.3 & 0.4 & 2.6 & 84.4 \\
\hline VET & 17 & 3.3 & 19.5 & 10.9 & 9.2 & 9 & 2.9 & 5.3 & 1.3 & 0.5 & 2.4 & 1.3 & 2 & 12.5 & 1.2 & 1.8 & 87.5 \\
\hline LINK & 14.5 & 7.3 & 17.2 & 13.2 & 7.2 & 5.3 & 1.4 & 1.3 & 2.5 & 1.1 & 2.6 & 2.1 & 1.8 & 2.9 & 15.9 & 3.7 & 84.1 \\
\hline THETA & 19.5 & 0.1 & 4.9 & 0.3 & 0.1 & 1.6 & 1 & 0.6 & 0.5 & 1 & 1.7 & 2.5 & 0.1 & 0.4 & 0.2 & 65.5 & 34.5 \\
\hline TO & 249.2 & 56.6 & 261.1 & 141.4 & 97.6 & 106.1 & 41.7 & 25.4 & 26.9 & 16.8 & 44.2 & 27.1 & 19.3 & 25.5 & 13.4 & 42.9 & 1195.2 \\
\hline NET & 239.6 & 76 & 231.9 & 82 & 69.4 & 70.5 & -34.7 & -45.8 & -54.9 & -62.6 & -29.6 & -56.7 & -49.5 & -49.5 & -54.8 & 73.8 & - \\
\hline
\end{tabular}

Table 5: DY index under D8.

\begin{tabular}{|c|c|c|c|c|c|c|c|c|c|c|c|c|c|c|c|c|c|}
\hline & BTC & USDT & XLM & ETH & $\mathrm{BNB}$ & XEM & LTC & XRP & EOS & DASH & XMR & $\mathrm{BCH}$ & DOGE & VET & LINK & THETA & FROM \\
\hline BTC & 82.2 & 3.6 & 1.5 & 0.9 & 1.8 & 2.4 & 2.3 & 0.9 & 0.1 & 0 & 0.5 & 0.8 & 1 & 0.2 & 0.3 & 1.5 & 17.8 \\
\hline USDT & 42.4 & 46.2 & 1.6 & 0.2 & 2.3 & 1.4 & 0.8 & 0.4 & 0 & 0 & 1.3 & 0.4 & 1.2 & 0.1 & 0 & 1.7 & 53.8 \\
\hline XLM & 49.4 & 1.5 & 37.1 & 1.8 & 2.8 & 0.5 & 0.7 & 1.3 & 0.6 & 0.2 & 0.2 & 0.5 & 0.8 & 0.2 & 0.9 & 1.3 & 62.9 \\
\hline ETH & 75 & 3 & 3.3 & 7.6 & 1.7 & 2 & 2.2 & 0.6 & 0.2 & 0.1 & 0.3 & 0.9 & 1 & 0.1 & 0.4 & 1.5 & 92.4 \\
\hline BNB & 62.9 & 4.4 & 2.5 & 1.1 & 21.5 & 1.1 & 2 & 0.9 & 0 & 0 & 0.3 & 0.5 & 0.6 & 0.1 & 0.1 & 1.9 & 78.5 \\
\hline XEM & 52.3 & 2.1 & 16.8 & 1.2 & 2.4 & 17.2 & 2 & 0.2 & 0.4 & 0.6 & 0.2 & 0.5 & 1.1 & 0.4 & 0.6 & 2.1 & 82.8 \\
\hline LTC & 66.6 & 3.2 & 7.2 & 2.1 & 2.3 & 3.8 & 10.3 & 0.5 & 0.2 & 0.1 & 0.1 & 0.3 & 0.5 & 0.2 & 0.1 & 2.3 & 89.7 \\
\hline XRP & 54.2 & 2.2 & 25.6 & 0.9 & 2.5 & 2.6 & 1.4 & 5.2 & 0.8 & 0.1 & 0.3 & 0.9 & 1 & 0.4 & 0.6 & 1.3 & 94.8 \\
\hline EOS & 71.6 & 3.4 & 4.4 & 2.6 & 2.8 & 1.8 & 3.4 & 0.4 & 5.6 & 0 & 0.3 & 0.6 & 1.1 & 0.2 & 0.2 & 1.6 & 94.4 \\
\hline DASH & 72.7 & 3.4 & 2.7 & 2.1 & 1.7 & 1.7 & 1.8 & 1.7 & 1.3 & 7.4 & 0.5 & 0.7 & 0.8 & 0.2 & 0.2 & 1.2 & 92.6 \\
\hline XMR & 8.8 & 22.3 & 11.8 & 2.1 & 2.1 & 3.3 & 3.2 & 0.9 & 0.4 & 0.2 & 41.2 & 0.2 & 1 & 1.4 & 0.3 & 0.9 & 58.8 \\
\hline $\mathrm{BCH}$ & 54.7 & 2.3 & 19.2 & 2.6 & 2.6 & 2.4 & 1.6 & 0.4 & 0.4 & 0.4 & 0.4 & 8.9 & 0.8 & 0.3 & 0.7 & 2.3 & 91.1 \\
\hline DOGE & 63.4 & 5.4 & 2.9 & 0.6 & 9.1 & 0.7 & 2.1 & 0.7 & 0.2 & 0 & 0.5 & 0.3 & 11.4 & 0 & 0.1 & 2.6 & 88.6 \\
\hline VET & 65.5 & 4 & 7.2 & 1.3 & 4.8 & 2.8 & 1.6 & 0.6 & 0.3 & 0.2 & 0.4 & 0.8 & 0.9 & 7.7 & 0.5 & 1.5 & 92.3 \\
\hline LINK & 59.1 & 2.9 & 18.8 & 2.3 & 2.2 & 2 & 1.9 & 0.2 & 0.5 & 0.3 & 0.1 & 0.8 & 0.9 & 0.2 & 6.5 & 1.1 & 93.5 \\
\hline THETA & 9.1 & 41.3 & 0.6 & 0.2 & 0.7 & 0.2 & 1.4 & 0.1 & 0.4 & 0.2 & 16.3 & 0.5 & 0.2 & 0.2 & 0.1 & 28.6 & 71.4 \\
\hline TO & 807.6 & 105.1 & 126 & 22 & 41.8 & 28.7 & 28.1 & 10 & 5.9 & 2.5 & 21.8 & 8.6 & 12.8 & 4.5 & 5.3 & 24.6 & 1255.4 \\
\hline NET & 871.9 & 97.4 & 100.2 & -62.7 & -15.2 & -36.8 & -51.3 & -79.6 & -82.9 & -82.6 & 4.2 & -73.6 & -64.4 & -80.1 & -81.7 & -18.2 & - \\
\hline
\end{tabular}




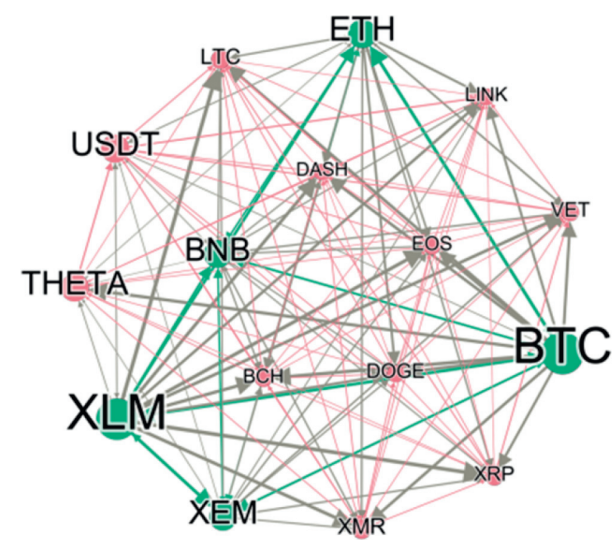

FIgure 26: Risk spillover under D1.

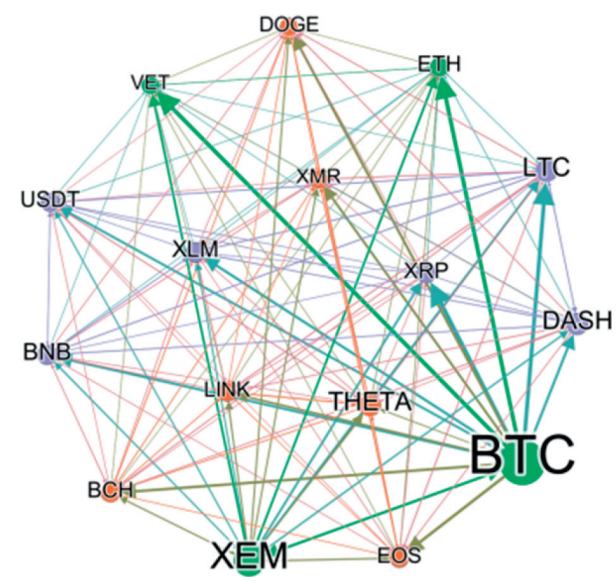

FIgURE 27: Risk spillover under D2.

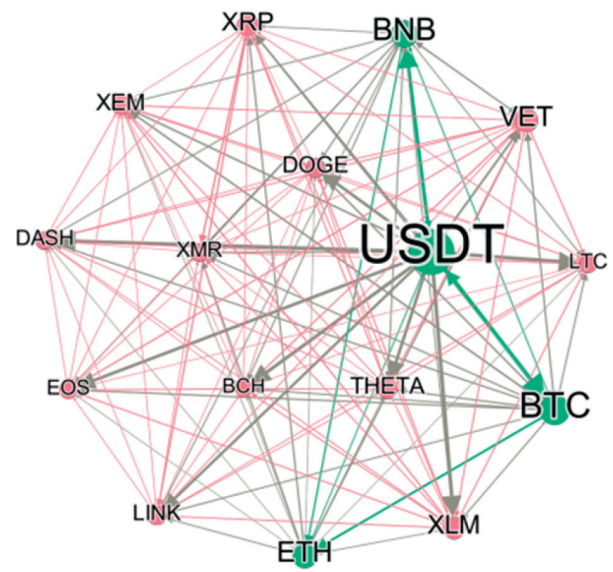

Figure 28: Risk spillover under D3.

refers to the risk spillover value between the two. The "NET" in the bottom row refers to the net spillover effect of a certain cryptocurrency, that is, the value of the output of the "IN" column offsetting the input of "OUT." According to the risk spillover table, we can see that the net risk spillover intensity on D1 and D8 has dropped from $405 \%$ to $345 \%$, and the

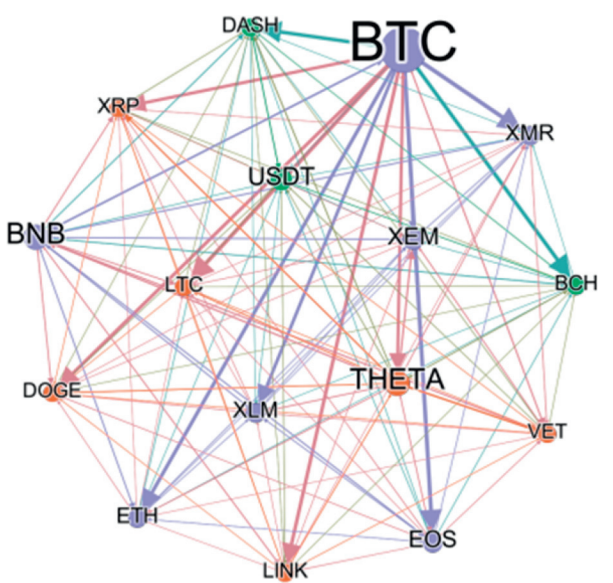

Figure 29: Risk spillover under D4.

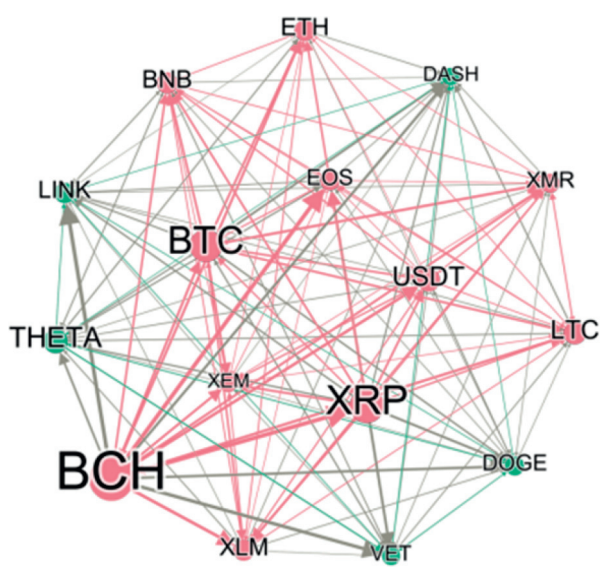

Figure 30: Risk spillover under D5.

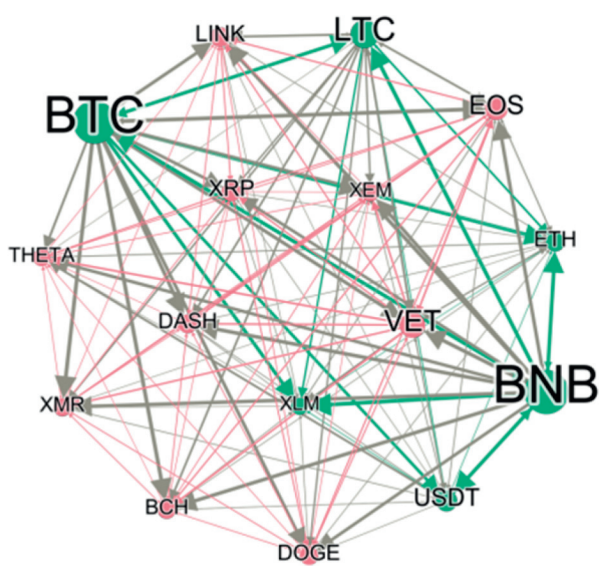

Figure 31: Risk spillover under D6.

effect of visible frequency is obvious. Then, we will draw networks of risk spillovers at different frequencies, as shown in Figures 26-33, to specifically look at the risk infection path between different cryptocurrencies. 


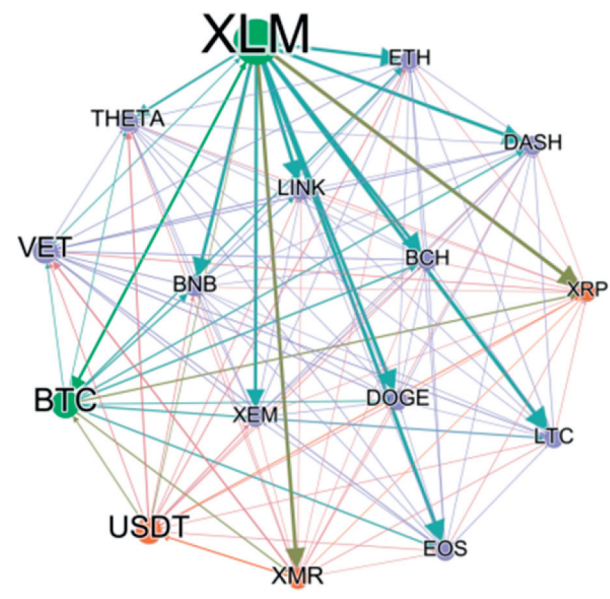

FIgURe 32: Risk spillover under D7.

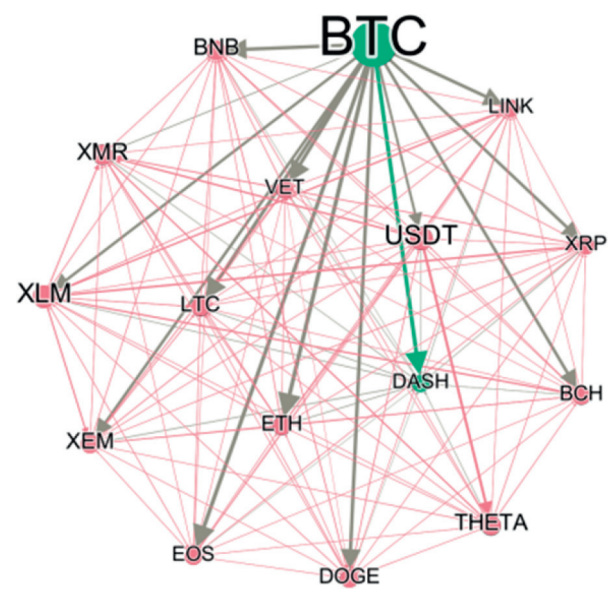

Figure 33: Risk spillover under D8.

The risk infection network consists of nodes and edges with arrows. The size of the node is set according to the weighted-out degree, that is, the net risk spillover represented by the NET column value of spillover matrix (Table 4) as the weight. The larger the net overflow, the larger the node. The color of the node is colored according to the "modularity" value in the "Gephi" statistical attribute, which means that the similarity of the risk value between different cryptocurrencies shows the same community attribute, and the color of the edge also changes accordingly. The size of the edge is expressed as the weight based on the intermediate value of the spillover matrix (Table 4), that is, the degree of risk spillover between the two. On the whole, the risk spillover of BTC in the medium and long term is relatively stable, except for D7, which is affected by the same modular spillover of XLM. The modularity of these frequencies always changes, but the big picture remains consistent in the long term (D1-D3), just like that the internal spillover of the first two intervals are maintained, and the latter is more entering, which is affected by USDT. But when the frequency is in the mid-term (D4) and the shortest term (D8), BTC becomes the only module by itself, with a strong spillover effect on other cryptocurrencies, which generates risk spillovers, while the rest is modular radiation, alongside light power. In the following figures, when BTC remains stable, the rest of the Bitcoins are also followed behind closely. In the long run, at D1, XLM and BTC have reached the point where they resist courtesy, while at D3, USDT has far surpassed BTC, accompanying rapid changes. In the mid-term, at $\mathrm{D} 5, \mathrm{BCH}$ surpassed BTC, with a strong risk of spilling infection to BTC, and at the same time radiating to other cryptocurrencies with modularity. In the short term, at D6, BNB and BTC have the same strong risk spillover. For these cryptocurrencies that are about to approach or have become risk centers at different frequencies, the risk center changes of XLM, BCH, and USDT (Figures 11, 12, and 21) have a strong correlation with causality, while BNB is abnormal (Figure 14). At high frequencies, the causality diagram is light blue, which is a weaker causality, but under the DY matrix, it becomes the risk spillover center in D6. However, $\mathrm{BCH}$ is a comprehensive red in the causality diagram, with a very strong causal relationship, but it only becomes the center at D5, and the other frequencies have very little influence. This provides a basis for further research on nonlinear systemic risks.

4.3. STVAR Model Based on WPT. In order to ensure that the introduction of periodicity is theoretically reasonable, we conduct a nonlinear test before STVAR model estimation. We use BDS test [68], Quandt-Andrews test [83, 84], and Bai-Perron test [85] to test the stability of model parameters. Among them, the Quandt-Andrews test is the unknown mutation point test, and the Bai-Perron test is the multiple mutations in the unknown inspection. Table 6 shows the results of the parameter stability of the systemic risk evaluation of each cryptocurrency. For the BDS test, when the nesting dimensions are 3,4, and 5, the null hypothesis of independent and identical distribution is significantly rejected, indicating that there is a nonlinear relationship between the variables; that is, it has the characteristic of being transformable [86, 87]. The mutation point test indicates that the parameters of the model contain one or more mutation points, which means that the use of constant parameter estimation methods will lead to biased model estimation results.

Based on the partial conflict between the abovementioned causality and the risk spillover network, we reissue the STVAR model to further explore the risk spillover of different states under the same frequency. The highlight of the STVAR model lies in the state variable CRIX, which is different from the DY matrix. We use HP filtering (Hodrick-Prescott filter) to extract the period term of the market index, and the conversion of state variables will divide the original data into upward and downward intervals, that is, expansion and recession. In addition, in the STVAR model, we take the forecast period as 60 periods. The following data takes the 60th period as an example (we have observed the risk spillover centers of periods $4,8,16,32$, and 60 , respectively, and they are all consistent. The results are available on request). The result of the variance 
TABLe 6: Mutation point test at D1.

\begin{tabular}{|c|c|c|c|c|c|}
\hline \multicolumn{2}{|c|}{ BDS test at D1 } & \multicolumn{2}{|c|}{ Quandt-Andrews test at D1 } & \multicolumn{2}{|c|}{ Bai-Perron test at D1 } \\
\hline Dimension & $Z$-statistic & Statistic & Value & Breaks & Weighted $F$-statistic \\
\hline 2 & $35.87334^{* * *}$ & Max LR & $27.27269^{* * *}$ & 1 & $145.1847^{* * *}$ \\
\hline 3 & $36.20612^{* * *}$ & Max Wald & $436.3631^{* * *}$ & 2 & $434.7727^{* * *}$ \\
\hline 4 & $36.53463^{* * *}$ & Exp LR & $11.24758^{* * *}$ & 3 & $582.5047^{* * *}$ \\
\hline 5 & $37.66492^{* * *}$ & Exp Wald & $212.3472^{* * *}$ & 4 & $634.7938^{* * *}$ \\
\hline \multirow[t]{2}{*}{6} & $39.70935^{* * *}$ & Ave LR & $14.25429^{* * *}$ & 5 & $702.3262^{* * *}$ \\
\hline & & Ave Wald & $228.0686^{* * *}$ & & \\
\hline \multicolumn{2}{|c|}{ BDS test at D8 } & \multicolumn{2}{|c|}{ Quandt-Andrews test at D8 } & \multicolumn{2}{|c|}{ Bai-Perron test at D8 } \\
\hline Dimension & $Z$-statistic & Statistic & Value & Breaks & Weighted $F$-statistic \\
\hline 2 & $26.60005^{* * *}$ & Max LR & $29.01095^{* * *}$ & 1 & $464.1752^{* * *}$ \\
\hline 3 & $27.80135^{* * *}$ & Max Wald & $464.1752^{* * *}$ & 2 & $477.6903^{* * *}$ \\
\hline 4 & $29.49901^{* * *}$ & Exp LR & $12.44368^{* * *}$ & 3 & $518.6559^{* * *}$ \\
\hline 5 & $31.52829^{* * *}$ & Exp Wald & $227.7935^{* * *}$ & 4 & $567.7082^{* * *}$ \\
\hline \multirow[t]{2}{*}{6} & $33.63134^{* * *}$ & Ave LR & $18.9412^{* * *}$ & 5 & $582.9202^{* * *}$ \\
\hline & & Ave Wald & $303.0592^{* * *}$ & & \\
\hline
\end{tabular}

Notes: (1) BDS test is based on the residual series. (2) Bai-Perron test is measured at "Global $L$ breaks versus none" and the maximum mutation points set at Eviews10 is 5.

decomposition results in a superposition of decimal points and cannot be listed in a limited page. Therefore, we only show the data of the two states of BTC at the frequency of D1 and D8, that is, risk spillover for other cryptocurrencies (including itself)), as shown in Table 7.

The following shows the risk spillover network in different states (regimes) at different frequencies, and its specific properties are the same as the above network diagram. On the whole, under different regimes, the risk center may change, or the risk intensity may change. Under D1, BTC is the center of risk in expansion, followed by 5 currencies with different net risk spillover including XLM and XEM in Figure 26, while in recession, only BTC is the center, and nothing followed. Comparing to the DY matrix, its comprehensive risk module will remain consistent. Under D2, it is in sharp contrast with the DY matrix. The former is the dominant BTC, but at this time, there are multiple risk centers in both regimes. In recession, the risk centers not only become DASH and XMR, but BTC only has minimal net risk spillover. Under D3, USDT exists in the risk centers of both, which is consistent with the DY matrix. In recession, we can see that DOGE has even become a risk spillover center that surpasses USDT, which echoes the red and blue causality diagram (Figure 22). Under D4, when the risk spillover center maintained the foundation of BTC, XMR gradually became stronger, until in recession, surpassing BTC became the only one. Under D5, the original degree of risk spillover under DY matrix is magnified. In recession, DOGE becomes an important force for shocking risk. Compared with the center, XMR is more significant in recession, and XRP is more significant in expansion. The difference is that the modularity effect has disappeared; thus the attributes shown by different cryptocurrencies show the characteristics of homogeneity. Under D6, the risk spillover effect of BTC seems to be weakened, and BNB occupies the center position. At the same time, when transitioning from $R$ to $E$, the modularization is increased to 3 layers. The increase in modularity has impacted BTC's risk center position. Under D7, the
TABLe 7: Variance decomposition under D1 and D8.

\begin{tabular}{lcccc}
\hline & E1 & R1 & E8 & R8 \\
\hline BTC & 0.031598862 & 0.331499371 & 0.162869273 & 0.367568582 \\
USDT & 0.022759805 & 0.322926561 & 0.159920324 & 0.360501403 \\
XLM & 0.029465532 & 0.299483116 & 0.129024966 & 0.304571259 \\
ETH & 0.03334609 & 0.291689594 & 0.154070093 & 0.354073605 \\
BNB & 0.027358849 & 0.320791552 & 0.146497214 & 0.351841821 \\
XEM & 0.02700427 & 0.29718005 & 0.136677786 & 0.318404742 \\
LTC & 0.030847272 & 0.307208371 & 0.146460891 & 0.338103864 \\
XRP & 0.029534455 & 0.294918714 & 0.137492015 & 0.321451507 \\
EOS & 0.030994604 & 0.285515889 & 0.150972283 & 0.353127934 \\
DASH & 0.030571503 & 0.292677478 & 0.144059299 & 0.344757499 \\
XMR & 0.029445069 & 0.310724834 & 0.078361147 & 0.173421102 \\
BCH & 0.029513472 & 0.313196399 & 0.133429574 & 0.312831387 \\
DOGE & 0.030496163 & 0.289546516 & 0.144039877 & 0.347102666 \\
VET & 0.029977661 & 0.305307092 & 0.147001788 & 0.343447659 \\
LINK & 0.027388662 & 0.304459542 & 0.139891139 & 0.327138017 \\
THETA & 0.029643945 & 0.322797859 & 0.087202167 & 0.235510653 \\
\hline
\end{tabular}

expansion is consistent with the DY matrix, while the recession allows USDT increasing. Under D8, XLM replaces BTC as the center in expansion. Fousekis and Tzaferi believe that returns are more likely to have a fundamental change in causality [88], and the systemic risk of network differs. This may be the explanation.

In the abovementioned, all figures of different regimes under different frequencies are shown from Figures 34-49; besides, the previously emerging $\mathrm{BCH}$, USDT, and $\mathrm{BNB}$, even XEM and XMR occupying a small market value can become the center of risk spillover. On the whole, the conclusion that BTC, as a risk spillover center, is more credible, but it is also necessary to consider the possibility of different frequencies and regimes; that is, BTC has strong risk spillover in the longest (D1) and shortest (D8) periods, and it will be more robust in expansion. For other small cryptocurrencies, medium-term holdings and recession periods will be more stable. When examining the changes between different regimes, even DOGE, whose causality is 


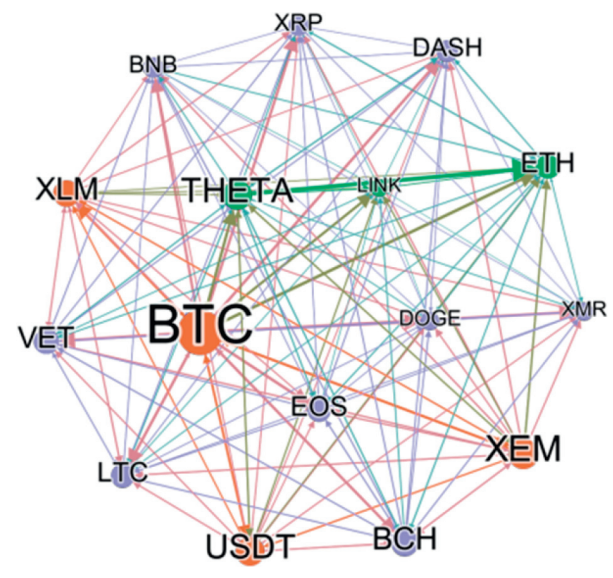

FIgURE 34: Risk spillover under E1.

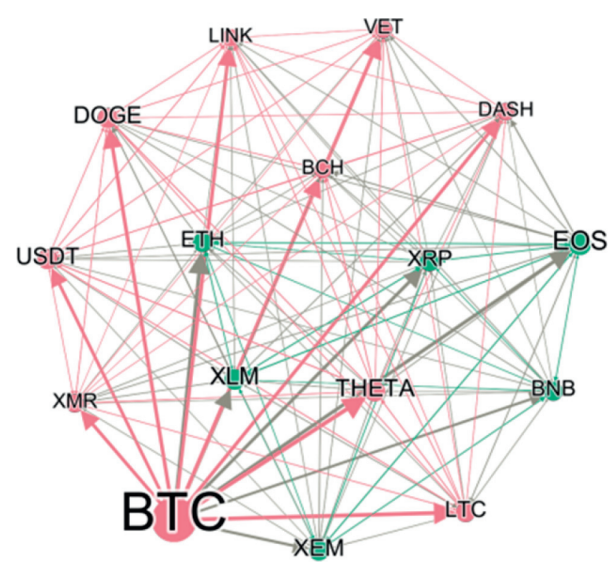

FIgURE 35: Risk spillover under R1.

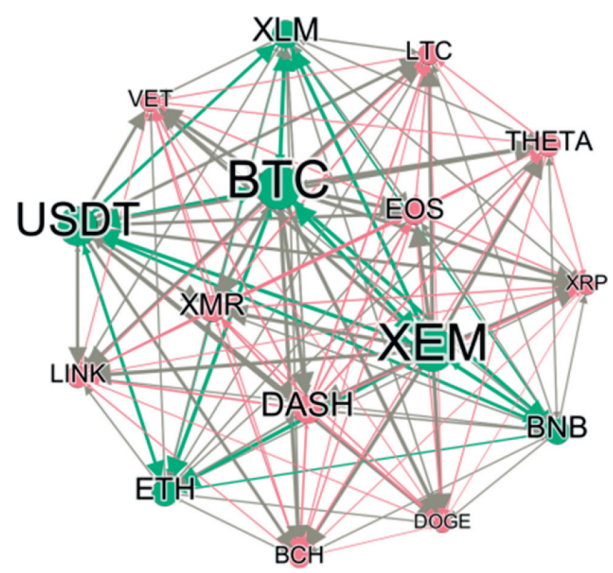

FIGURE 36: Risk spillover under E2.

weak through each frequency, has become the center of risk spillover in recession of D3 and D5, and more potential possibilities need to be excavated in different regimes. It can be seen that the nonlinear causality test based on the logarithmic rate of return cannot accurately correspond to the risk spillover relationship, and based on the wavelet packet

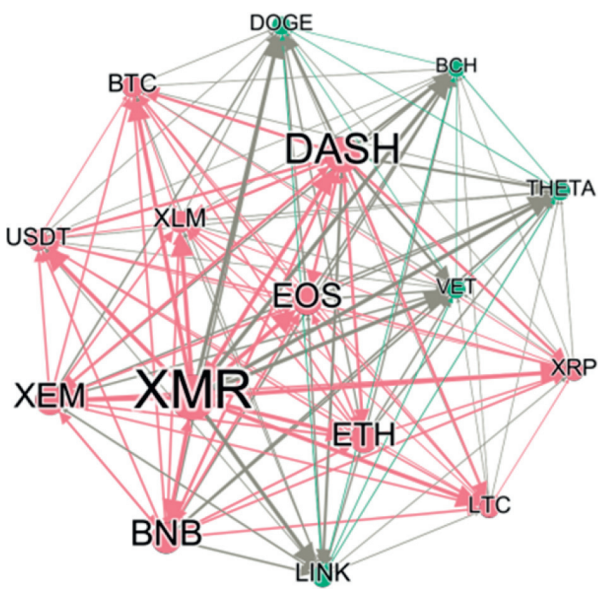

FIgURe 37: Risk spillover under R2.

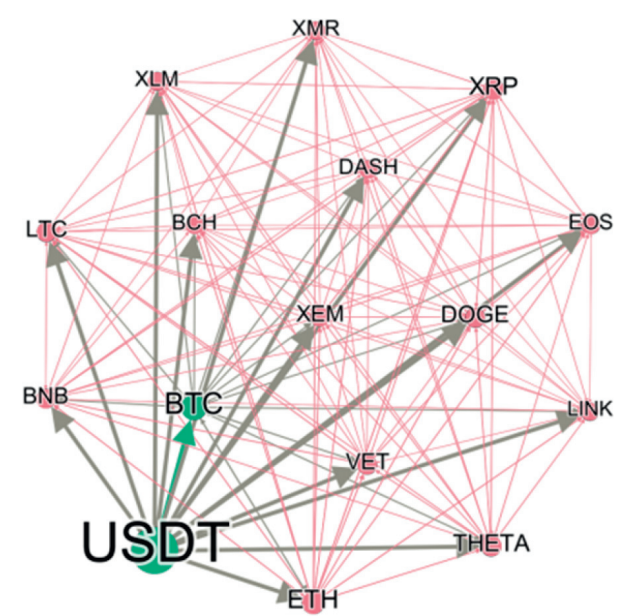

FIgURE 38: Risk spillover under E3.

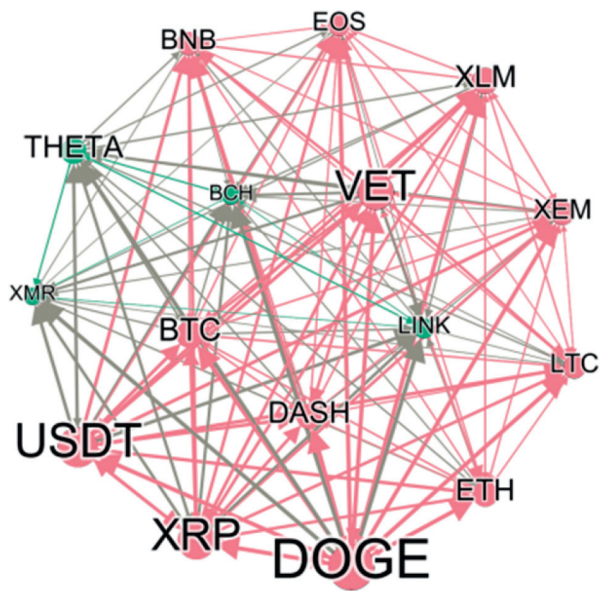

Figure 39: Risk spillover under R3.

decomposition, the overall result transmitting from the DY matrix to the STVAR model is reasonable. Not only does it examine the changes under frequency, but also it sees 


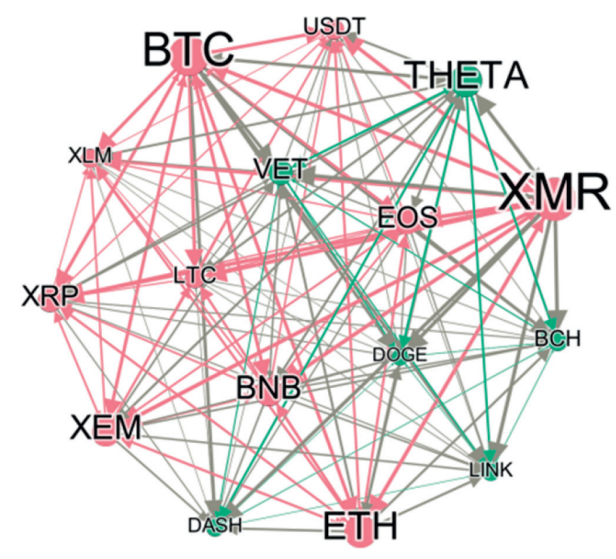

FIgURE 40: Risk spillover under E4.

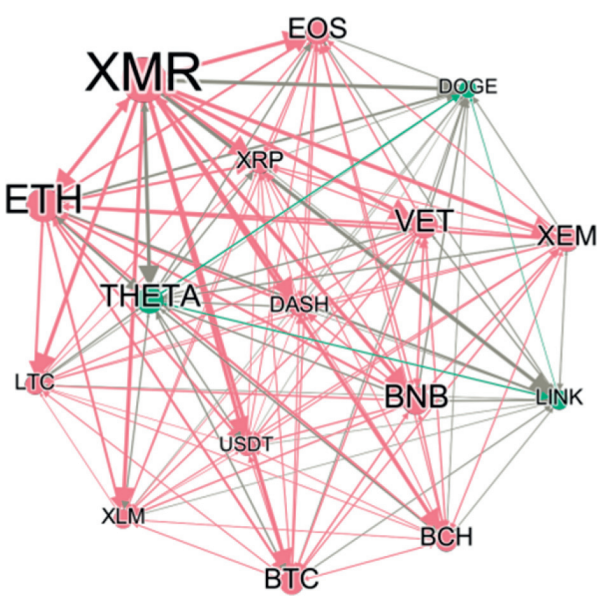

Figure 41: Risk spillover under R4.

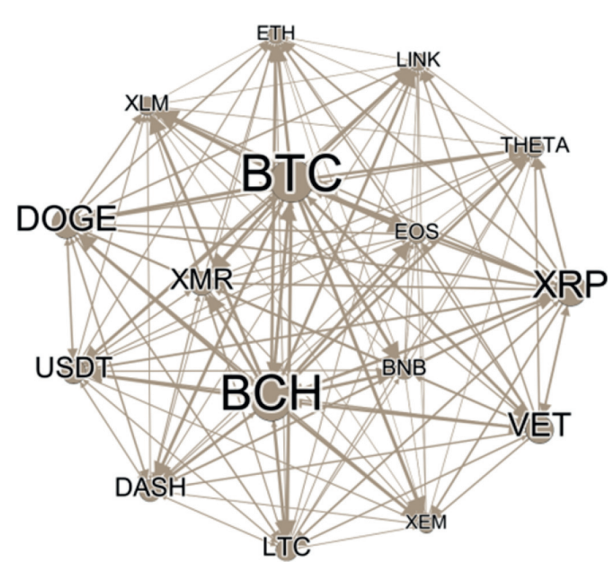

FIGURE 42: Risk spillover under E5.

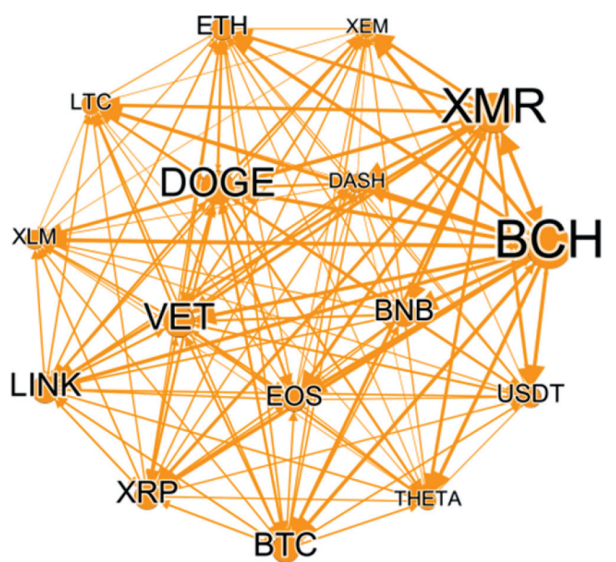

Figure 43: Risk spillover under R5.

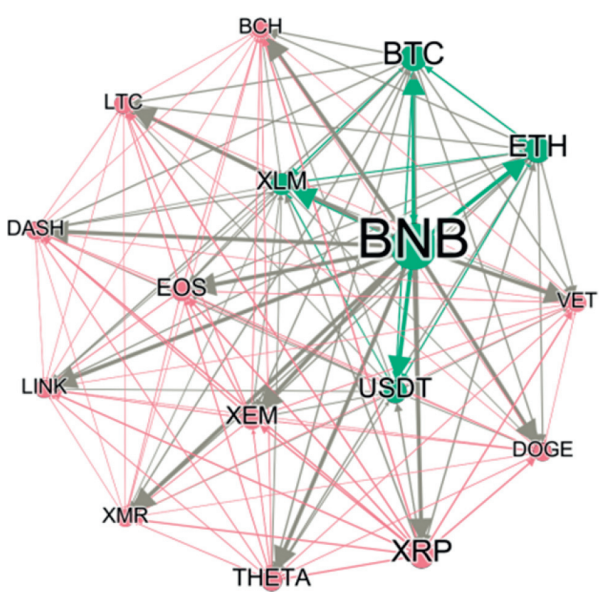

Figure 44: Risk spillover under E6.

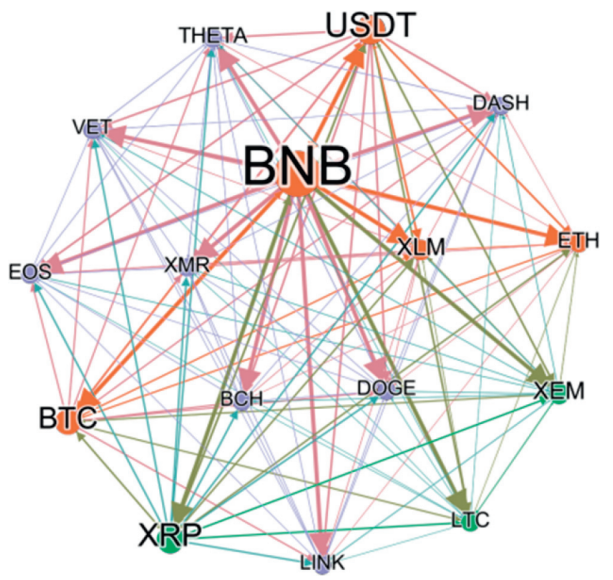

FIgURE 45: Risk spillover under R6. 


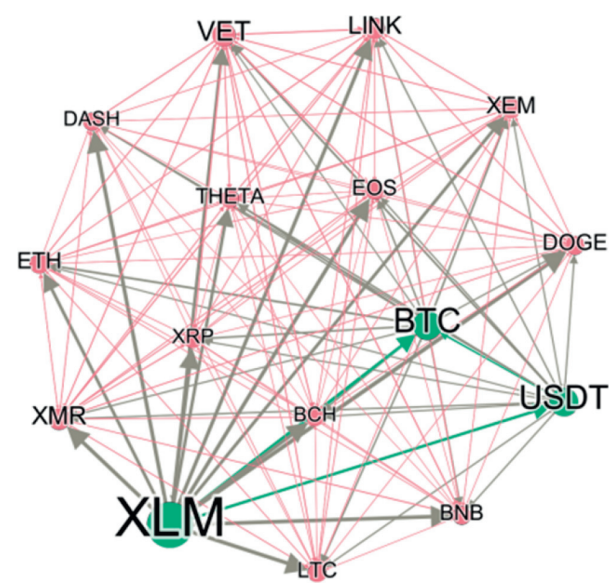

FIgURE 46: Risk spillover under E7.

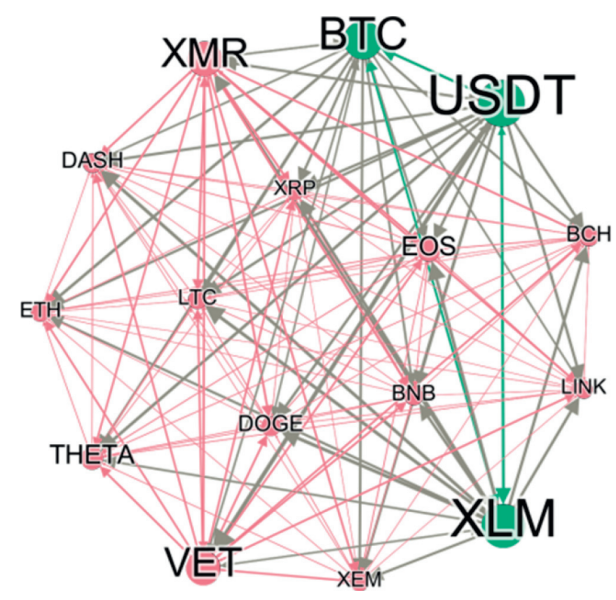

FIgURE 47: Risk spillover under R7.

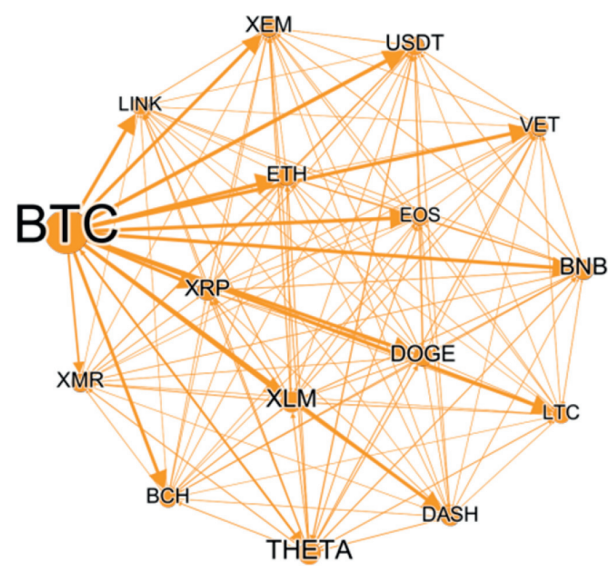

FIgURE 48: Risk spillover under E8.

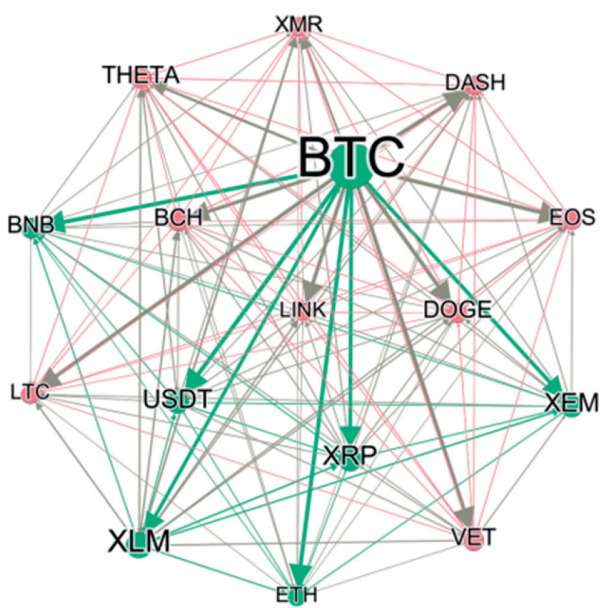

Figure 49: Risk spillover under R8.

changes under different regimes, and more detailed trends may need to consider more mutation points.

\section{Conclusion}

This research uses diversified investment portfolios as the main driving force. By combining wavelet packet decomposition with nonlinear Granger causality test, risk overlap network, and STVAR model, they are linked together to improve the systemic risk research system in practice. Our research is based on the systemic risk research under the time and frequency. For one thing, we transform and optimize the traditional wavelet decomposition into wavelet packet decomposition; also, we use the STVAR model to explore the changes of risk spillover centers under different regimes. We found that BTC has always remained strong in the longest and shortest terms, and it performs better when it enters the expansion period. The cryptocurrency with a small market value may enter breakthrough in the medium term, and the recession period is an important moment of turnaround. For the holding period and investment types, investors need to consider their risks comprehensively.

This research reveals the possibility of introducing macro variables, that is, to make rational use of the connection between the cryptocurrency market and other markets. Will the overall changes in other markets also have the effect of shifting and replacing the risk spillover of the cryptocurrency market, which is worth studying? However, it must be admitted that although cryptocurrencies with a small market capitalization have the potential to break through during the recession period, currencies such as BTC have been influenced, but still stable. The specific game between 
the dominant currency and the small currency on a timefrequency basis is a topic waiting to be resolved.

\section{Data Availability}

The original data were obtained from https://cn.investing. com and http://thecrix.de.

\section{Conflicts of Interest}

The authors declare that they have no conflicts of interest regarding the publication of this paper.

\section{Acknowledgments}

This work was supported by the National Natural Science Foundation of China (Grant no. 71903097), the Humanity and Social Science Youth Foundation of Ministry of Education of China (Grant no. 18YJC790226), the Social Science Foundation of Jiangsu Province (Grant no. 20EYC011), and the Natural Science Foundation of Jiangsu Province (Grant no. BK20190767).

\section{References}

[1] S. Nakamoto, "Bitcoin: a peer-to-peer electronic cash system," 2008, https://bitcoin.org/bitcoin.pdf.

[2] M. Polasik, A. I. Piotrowska, T. P. Wisniewski, R. Kotkowski, and G. Lightfoot, "Price fluctuations and the use of bitcoin: an empirical inquiry," International Journal of Electronic Commerce, vol. 20, no. 1, pp. 9-49, 2015.

[3] E. Bouri, S. J. H. Shahzad, D. Roubaud, L. Kristoufek, and B. Lucey, "Bitcoin, gold, and commodities as safe havens for stocks: new insight through wavelet analysis," The Quarterly Review of Economics and Finance, vol. 77, pp. 156-164, 2020.

[4] G. Selgin, "Synthetic commodity money," Journal of Financial Stability, vol. 17, pp. 92-99, 2015.

[5] X. Li and C. A. Wang, "The technology and economic determinants of cryptocurrency exchange rates: the case of Bitcoin," Decision Support Systems, vol. 95, pp. 49-60, 2017.

[6] E. Bouri, N. Jalkh, P. Molnárbcd, and D. Roubaud, "Bitcoin for energy commodities before and after the December 2013 crash: diversifier, hedge or safe haven?" Applied Economics, vol. 49, no. 50, pp. 5063-5073, 2017.

[7] M. Briere, K. Oosterlinck, and A. Szafarz, "Virtual currency, tangible return: portfolio diversification with bitcoin," Journal of Asset Management, vol. 16, no. 6, pp. 365-373, 2015.

[8] A. H. Dyhrberg, "Bitcoin, gold and the dollar-a GARCH volatility analysis," Finance Research Letters, vol. 16, pp. 8592, 2016

[9] T. Klein, H. Pham Thu, and T. Walther, "Bitcoin is not the new gold-a comparison of volatility, correlation, and portfolio performance," International Review of Financial Analysis, vol. 59, pp. 105-116, 2018.

[10] N. Kyriazis, S. Papadamou, and S. Corbet, "A systematic review of the bubble dynamics of cryptocurrency prices," Research in International Business and Finance, vol. 54, 2020.

[11] J. Fry and E.-T. Cheah, "Negative bubbles and shocks in cryptocurrency markets," International Review of Financial Analysis, vol. 47, pp. 343-352, 2016.

[12] E.-T. Cheah and J. Fry, "Speculative bubbles in Bitcoin markets? an empirical investigation into the fundamental value of Bitcoin," Economics Letters, vol. 130, pp. 32-36, 2015.

[13] F. A. Enoksen, C. J. Landsnes, K. Lučivjanská, and P. Molnár, "Understanding risk of bubbles in cryptocurrencies," Journal of Economic Behavior \& Organization, vol. 176, pp. 129-144, 2020.

[14] C. Chen, L. Liu, and N. Zhao, "Fear sentiment, uncertainty, and bitcoin price dynamics: the case of COVID-19," Emerging Markets Finance and Trade, vol. 56, no. 10, pp. 2298-2309, 2020.

[15] T. Conlon and R. McGee, "Safe haven or risky hazard? bitcoin during the COVID-19 bear market," Finance Research Letters, vol. 35, Article ID 101607, 2020.

[16] P. K. Sahoo, "COVID-19 pandemic and cryptocurrency markets: an empirical analysis from a linear and nonlinear causal relationship," Studies in Economics and Finance, 2021.

[17] R. Li, S. Li, D. Yuan, and H. Zhu, "Investor attention and cryptocurrency: evidence from wavelet-based quantile Granger causality analysis," Research in International Business and Finance, vol. 56, 2021.

[18] S. H. Kang, R. P. McIver, and J. A. Hernandez, "Comovements between Bitcoin and Gold: a wavelet coherence analysis," Physica A: Statistical Mechanics and its Applications, vol. 536, Article ID 120888, 2019.

[19] W. Fruehwirt, L. Hochfilzer, L. Weydemann, and S. Roberts, "Cumulation, crash, coherency: a cryptocurrency bubble wavelet analysis," Finance Research Letters, vol. 40, Article ID 101688, 2021.

[20] V. Celeste, S. Corbet, and C. Gurdgiev, "Fractal dynamics and wavelet analysis: deep volatility and return properties of Bitcoin, Ethereum and Ripple," The Quarterly Review of Economics and Finance, vol. 76, pp. 310-324, 2020.

[21] N. Rhaeim, S. B. Ammou, and A. B. Mabrouk, "Wavelet estimation of systematic risk at different time scales: application to French stock market," The International Journal of Applied Economics and Finance, vol. 1, no. 2, pp. 113-119, 2007.

[22] V. Fernandez, "The CAPM and value at risk at different timescales," International Review of Financial Analysis, vol. 15, no. 3, pp. 203-219, 2006.

[23] K. Guesmi, S. Saadi, I. Abid, and Z. Ftiti, "Portfolio diversification with virtual currency: evidence from bitcoin," International Review of Financial Analysis, vol. 63, pp. 431-437, 2019.

[24] Z. Tu and C. Xue, "Effect of bifurcation on the interaction between bitcoin and litecoin," Finance Research Letters, vol. 31, 2019.

[25] S. Corbet, D. J. Cumming, B. M. Lucey, M. Peat, and S. A. Vigne, "The destabilising effects of cryptocurrency cybercriminality," Economics Letters, vol. 191, Article ID 108741, 2020.

[26] M. J. Kim, N. P. Canh, and S. Y. Park, "Causal relationship among cryptocurrencies: a conditional quantile approach," Finance Research Letters, Article ID 101879, 2020.

[27] D. Louzis, "Measuring spillover effects in Euro area financial markets: a disaggregate approach," Empirical Economics, vol. 49, no. 4, pp. 1367-1400, 2015.

[28] S. Yi, Z. Xu, and G.-J. Wang, "Volatility connectedness in the cryptocurrency market: is Bitcoin a dominant cryptocurrency?" International Review of Financial Analysis, vol. 60, pp. 98-114, 2018.

[29] C. Beneki, A. Koulis, N. A. Kyriazis, and S. Papadamou, "Investigating volatility transmission and hedging properties 
between Bitcoin and Ethereum," Research in International Business and Finance, vol. 48, pp. 219-227, 2019.

[30] A. P. Fassas, S. Papadamou, and A. Koulis, "Price discovery in bitcoin futures," Research in International Business and Finance, vol. 52, Article ID 101116, 2020.

[31] R. Selmi, W. Mensi, S. Hammoudeh, and J. Bouoiyour, "Is Bitcoin a hedge, a safe haven or a diversifier for oil price movements? a comparison with gold," Energy Economics, vol. 74, pp. 787-801, 2018.

[32] G. S. Uddin, J. A. Hernandez, S. J. H. Shahzad, and A. Hedström, "Multivariate dependence and spillover effects across energy commodities and diversification potentials of carbon assets," Energy Economics, vol. 71, pp. 35-46, 2018.

[33] D. Wu and X. S. Zhao, "Systemic risk and bank failure," SSRN Electronic Journal, 2018.

[34] W. Feng, Y. Wang, and Z. Zhang, "Can cryptocurrencies be a safe haven: a tail risk perspective analysis," Applied Economics, vol. 50, no. 44, pp. 4745-4762, 2018.

[35] L. P. Hansen, Challenges in Identifying and Measuring Systemic Risk, University of Chicago Press, Chicago, IL, USA, 2014.

[36] F. Cortes, P. Linder, S. Malik, M. A. Segovaino, and U. S. Das, "A comprehensive multi-sector tool for analysis of systemic risk and interconnectedness (SyRIN)," International Monetary Fund, vol. 2018, no. 14, 2018.

[37] V. V. Acharya, "Measuring systemic risk," The Review of Financial Studies, vol. 30, no. 1, pp. 2-47, 2017.

[38] F. Reichert, Measuring Systemic Risk in Financial Institutions: a Factor-Copula Framework, Humboldt-Universität zu Berlin, Berlin, Germany, 2017.

[39] O. C. d. Silva Filho, F. A. Ziegelmann, and M. J. Dueker, "Modeling dependence dynamics through copulas with regime switching," Insurance: Mathematics and Economics, vol. 50, no. 3, pp. 346-356, 2012.

[40] J. Kurka, "Do cryptocurrencies and traditional asset classes influence each other?" Finance Research Letters, vol. 31, pp. 38-46, 2019.

[41] S. A. Manavi, G. Jafari, S. Rouhani, and M. Ausloos, "Demythifying the belief in cryptocurrencies decentralized aspects. A study of cryptocurrencies time cross-correlations with common currencies, commodities and financial indices," Physica A: Statistical Mechanics and its Applications, vol. 556, Article ID 124759, 2020.

[42] E. Bouri, B. Lucey, and D. Roubaud, "The volatility surprise of leading cryptocurrencies: transitory and permanent linkages," Finance Research Letters, vol. 33, 2020.

[43] A. B. Mabrouk, "Wavelet-based systematic risk estimation: application on GCC stock markets: the Saudi Arabia case," Quantitative Finance and Economics, vol. 4, no. 4, pp. 542-595, 2020.

[44] A. Cifter and A. Ozun, "Multiscale systematic risk: an application on ISE-30," 2007.

[45] R. Gençay, F. Selçuk, and B. Whitcher, "Multiscale systematic risk," Journal of International Money and Finance, vol. 24, no. 1, pp. 55-70, 2005.

[46] D. P. Percival, "On estimation of the wavelet variance," Biometrika, vol. 82, no. 3, pp. 619-631, 1995.

[47] J. B. Ramsey and C. Lampart, "Decomposition of economic relationships by timescale using wavelets," Macroeconomic Dynamics, vol. 2, no. 1, pp. 49-71, 1998.

[48] E. Bouri, T. Saeed, X. V. Vo, and D. Roubaud, "Quantile connectedness in the cryptocurrency market," Journal of International Financial Markets, Institutions and Money, vol. 71, Article ID 101302, 2021.
[49] D. Bianchi, M. Billio, R. Casarin, and M. Guidolin, "Modeling systemic risk with Markov switching graphical SUR models," Journal of Econometrics, vol. 210, no. 1, pp. 58-74, 2019.

[50] A. Almasri and G. Shukur, "An illustration of the causality relation between government spending and revenue using wavelet analysis on Finnish data," Journal of Applied Statistics, vol. 30, no. 5, pp. 571-584, 2003.

[51] L. Hahn Shik, "International transmission of stock market movements: a wavelet analysis," Applied Economics Letters, vol. 11, no. 3, pp. 197-201, 2004.

[52] G. Moratis, "Quantifying the spillover effect in the cryptocurrency market," Finance Research Letters, vol. 38, Article ID 101534, 2021.

[53] J. Zhou, "Smooth transition autoregressive models: a study of the industrial production index of Sweden," M. Sc thesis, Uppsala universitet, Uppsala, Sweden, 2010.

[54] T. Timo, D. Dick van, and M. C. Marcelo, "Linear models, smooth transition autoregressions and neural networks for forecasting macroeconomic time series: a reexamination," International Journal of Forecasting, vol. 21, no. 4, pp. 755$774,2005$.

[55] I. A. Venetis, I. Paya, and D. Peel, "ESTAR model with multiple fixed points," Testing and Estimation, 2009.

[56] M. Das, S. Kundu, and N. Sarkar, "Mean and volatility spillovers between REIT and stocks returns A STVARBTGARCH-M model," MPRA Paper, 2019.

[57] S. Soltani, "On the use of the wavelet decomposition for time series prediction," Neurocomputing, vol. 48, no. 1, pp. 267277, 2002

[58] S. Yousefi, I. Weinreich, and D. Reinarz, "Wavelet-based prediction of oil prices," Chaos, Solitons \& Fractals, vol. 25, no. 2, pp. 265-275, 2005.

[59] Z. Dong, "Calculation of noise resistance by use of the discrete wavelets transform," Electrochemistry Communications, vol. 3, no. 10, pp. 561-565, 2001.

[60] S. Aggarwal, L. Saini, and A. Kumar, "Electricity price forecasting in Ontario electricity market using wavelet transform in artificial neural network based model," International Journal of Control Automation and Systems, vol. 6, no. 5, pp. 639-650, 2008.

[61] J. B. Ramsey, "Wavelets in economics and finance: past and future," Studies in Nonlinear Dynamics \& Econometrics, vol. 6, no. 3, pp. 1-29, 2002.

[62] C. Huang, F. Gao, and H. Jiang, "Combination of biorthogonal wavelet hybrid kernel OCSVM with feature weighted approach based on EVA and GRA in financial distress prediction," Mathematical Problems in Engineering, vol. 2014, Article ID 538594, 2014.

[63] D. Štifanić, J. Musulin, A. Miočević, S. B. Šegota, R. Šubić, and Z. Car, "Impact of COVID-19 on forecasting stock prices: an integration of stationary wavelet transform and bidirectional long short-term memory," Complexity, vol. 2020, Article ID 1846926, 2020.

[64] S. Xiong, H. Zhou, S. He et al., "A novel end-to-end fault diagnosis approach for rolling bearings by integrating wavelet packet transform into convolutional neural network structures," Sensors, vol. 20, no. 17, Article ID 4965, 2020.

[65] C. Barile, C. Casavola, G. Pappalettera, and C. Pappalettera, "Detection of damage in CFRP by wavelet packet transform and empirical mode decomposition: an hybrid approach," Applied Composite Materials, vol. 27, no. 5, pp. 641-655, 2020.

[66] Z. Umar and M. Gubareva, "A time-frequency analysis of the impact of the COVID-19 induced panic on the volatility of 
currency and cryptocurrency markets," Journal of Behavioral and Experimental Finance, vol. 28, 2020.

[67] W. A. Brock, "Pathways to randomness in the economy: emergent nonlinearity and chaos in economics and finance," Estudios Económicos, vol. 8, no. 1, pp. 3-55, 1993.

[68] W. A. Broock, A. Scheinkman, W. D. Dechert, and B. LeBaron, "A test for independence based on the correlation dimension," Econometric Reviews, vol. 15, no. 3, pp. 197-235, 1996.

[69] C. Diks and V. Panchenko, "A new statistic and practical guidelines for nonparametric Granger causality testing," Journal of Economic Dynamics and Control, vol. 30, no. 9, pp. 1647-1669, 2006.

[70] P. K. Sahoo, D. Sethi, and D. Acharya, "Is bitcoin a near stock? linear and non-linear causal evidence from a price-volume relationship," International Journal of Managerial Finance, vol. 15, no. 4, pp. 533-545, 2019.

[71] M. Omane-Adjepong and I. P. Alagidede, "Multiresolution analysis and spillovers of major cryptocurrency markets," Research in International Business and Finance, vol. 49, pp. 191-206, 2019.

[72] C. Diks and M. Wolski, "Nonlinear granger causality: guidelines for multivariate analysis," Journal of Applied Econometrics, vol. 31, no. 7, pp. 1333-1351, 2016.

[73] V. Dičpinigaitienè and L. Novickytè, "Application of systemic risk measurement methods: a systematic review and metaanalysis using a network approach," Quantitative Finance and Economics, vol. 2, no. 4, pp. 798-820, 2018.

[74] F. X. Diebold and K. Y1lmaz, "On the network topology of variance decompositions: measuring the connectedness of financial firms," Journal of Econometrics, vol. 182, no. 1, pp. 119-134, 2014.

[75] C. A. Sims, "Macroeconomics and reality," Econometrica: Journal of the Econometric Society, pp. 1-48, 1980.

[76] T. Teräsvirta, "Specification, estimation, and evaluation of smooth transition autoregressive models," Journal of the American Statistical Association, vol. 89, no. 425, pp. 208-218, 1994.

[77] G. Caggiano, E. Castelnuovo, and J. M. Figueres, "Economic policy uncertainty and unemployment in the United States: a nonlinear approach," Economics Letters, vol. 151, pp. 31-34, 2017.

[78] P. Ciaian, M. Rajcaniova, and d. A. Kancs, "Virtual relationships: short- and long-run evidence from BitCoin and altcoin markets," Journal of International Financial Markets, Institutions and Money, vol. 52, pp. 173-195, 2018.

[79] T. L. D. Huynh, M. A. Nasir, X. V. Vo, and T. T. Nguyen, "“Small things matter most": the spillover effects in the cryptocurrency market and gold as a silver bullet," The North American Journal of Economics and Finance, vol. 54, Article ID 101277, 2020.

[80] A. B. Bortoluzzo, A. M. A. F. Minardi, and B. C. F. Passos, "Analysis of multi-scale systemic risk in Brazil's financial market," Revista de Administração, vol. 49, no. 2, pp. 240-250, 2014.

[81] E. Bouri, R. Gupta, A. K. Tiwari, and D. Roubaud, "Does bitcoin hedge global uncertainty? evidence from waveletbased quantile-in-quantile regressions," Finance Research Letters, vol. 23, pp. 87-95, 2017.

[82] Q. Xu, B. Jin, and C. Jiang, "Measuring systemic risk of the Chinese banking industry: a wavelet-based quantile regression approach," The North American Journal of Economics and Finance, vol. 55, Article ID 101354, 2021.
[83] R. E. Quandt, "Tests of the hypothesis that a linear regression system obeys two separate regimes," Journal of the American Statistical Association, vol. 55, no. 290, pp. 324-330, 1960.

[84] D. W. Andrews, "Tests for parameter instability and structural change with unknown change point," Econometrica: Journal of the Econometric Society, vol. 61, no. 4, pp. 821-856, 1993.

[85] J. Bai and P. Perron, "Computation and analysis of multiple structural change models," Journal of Applied Econometrics, vol. 18, no. 1, pp. 1-22, 2003.

[86] P. Fousekis and D. Tzaferi, "Returns and volume: frequency connectedness in cryptocurrency markets," Economic Modelling, vol. 95, pp. 13-20, 2021.

[87] C. Tan and C. N. S. Pedersen, "Financial time series forecasting using improved wavelet neural network," Master of Computer Science Faculty of Science, Univesity of Copenhagen, Copenhagen, Denmark, 2009.

[88] D. W. Andrews, "Tests for parameter instability and structural change with unknown change point," Econometrica: Journal of the Econometric Society, vol. 61, no. 4, pp. 821-856, 1993. 